\title{
Targeting Tyrosine Kinase Inhibitor-Resistant Non-Small Cell Lung Cancer by Inducing Epidermal Growth Factor Receptor Degradation via Methionine 790 Oxidation
}

\author{
Elaine Lai-Han Leung, Xing-Xing Fan,, Maria Pik Wong, ${ }^{2}$ Zhi-Hong Jiang, Zhong-Qiu Liu, ${ }^{3}$
} Xiao-Jun Yao, Lin-Lin Lu, ${ }^{3}$ Yan-Ling Zhou, Li-Fong Yau, Vicky Pui-Chi Tin,, and Liang Liu ${ }^{1}$

\begin{abstract}
Aims: Epidermal growth factor receptor (EGFR) tyrosine kinase inhibitors (TKIs) have been developed to treat non-small cell lung cancer (NSCLC) patients with EGFR mutation, but TKI resistance is common. Almost half of the acquired resistance patients are due to additional T790M mutation on EGFR (EGFR ${ }^{\mathrm{T} 790 \mathrm{M}}$ ), thus overcoming TKI resistance is important. In this study, we aim to investigate the role of reactive oxygen species (ROS) in TKI resistance as well as the molecular and biological effects of EGFR ${ }^{\mathrm{T} 790 \mathrm{M}}$ after redox manipulation. Results: The basal ROS levels in $\mathrm{EGFR}^{\mathrm{T} 790 \mathrm{M}}$-containing TKI-resistant NSCLC cell lines were substantially high. Sixty-three human lung tumors showed higher NADPH oxidase isoform 2 (NOX2) expression than normal lung tissues, which may contribute to high basal ROS in cancer and poor survival. Interestingly, only NOX3 was upregulated by sanguinarine, a pharmacological agent to elevate ROS, and resulted in EGFR overoxidation, degradation, and apoptosis. By contrast, such responses were lacking in EGFR ${ }^{\mathrm{WT}}$ cells. Selective $\mathrm{EGFR}^{\mathrm{T} 790 \mathrm{M}}$ degradation was manipulated by redox imbalance between NOX3 and methionine reductase A (MsrA). Furthermore, the in vivo tumor suppression effect of sanguinarine, NOX3 upregulation, and EGFR degradation were confirmed. Innovation: We have found a new treatment strategy to overcome TKI resistance by selectively inducing EGFR ${ }^{\mathrm{T} 790 \mathrm{M}}$ degradation via specific stimulation of methionine 790 (M790) oxidation. It can be achieved via manipulating redox imbalance between NOX3 and MsrA. Conclusion: Targeting EGFR by elevating ROS and redox imbalance is a potential new strategy to develop a new EGFR inhibitor for TKIresistant patients with a wide therapeutic window between EGFR $^{\mathrm{T} 790 \mathrm{M}}$ and EGFR ${ }^{\mathrm{WT}}$. Antioxid. Redox Signal.
\end{abstract} 24, 263-279.

\section{Introduction}

$\mathbf{P}$ ERSONALIZED THERAPY Is becoming a dominant cancer therapeutic strategy. Gefitinib, a first-generation epidermal growth factor receptor (EGFR) tyrosine kinase inhibitor (TKI), was first administered to non-small cell lung cancer
(NSCLC) patients 10 years ago (30), and personalized therapy has been increasingly utilized in cancer treatments (29, 41,42 ). However, acquired resistance to gefitinib (and other EGFR inhibitors) has become the most substantial obstacle for advancing EGFR-targeted treatment $(3,8,25,36)$. Approximately $50 \%$ of NSCLC patients develop acquired

\footnotetext{
${ }^{1}$ State Key Laboratory of Quality Research in Chinese Medicine, Macau Institute for Applied Research in Medicine and Health, Macau University of Science and Technology, Macau (SAR), China.

${ }^{2}$ Department of Pathology, Queen Mary Hospital, Li Ka Shing Faculty of Medicine, University of Hong Kong, Hong Kong (SAR), China.

${ }^{3}$ International Institute for Translational Chinese Medicine, Guangzhou University of Chinese Medicine, Guangzhou, China.

(c) Elaine Lai-Han Leung et al. 2015; Published by Mary Ann Liebert, Inc. This Open Access article is distributed under the terms of the Creative Commons Attribution Noncommercial License (http://creativecommons.org/licenses/by-nc/4.0/) which permits any noncommercial use, distribution, and reproduction in any medium, provided the original author(s) and the source are credited.
} 


\section{Innovation}

Epidermal growth factor receptor (EGFR) mutation is a key driving force of non-small cell lung cancer (NSCLC). Molecular targeting on EGFR using tyrosine kinase inhibitor (TKI) is effective initially, however, TKI resistance is common. The additional EGFR ${ }^{\mathrm{T} 790 \mathrm{M}}$ mutation is the major cause of resistance. In this study, we have reported a novel method to specifically target NSCLC with $\mathrm{EGFR}^{\mathrm{T} 790 \mathrm{M}}$ by localized elevation of reactive oxygen species, which triggers $\mathrm{EGFR}^{\mathrm{T} 790 \mathrm{M}}$ overoxidation and eventual degradation; such effect is absent in EGFR WT and other mutation forms, potentially with minimal offtarget and harmful effects to normal tissue. Our findings provide new insights into development of new class of EGFR-targeting therapeutics via triggering redox imbalance between NADPH oxidase (NOX) and methionine reductase A (MsrA) activity.

resistance due to eventually harboring an additional substitution mutation of threonine with methionine in EGFR at position 790 (EGFR $\left.{ }^{\mathrm{T} 790 \mathrm{M}}\right)(46)$.

To overcome TKI resistance, second-generation TKIs have been developed intensively by pharmaceutical companies, with afatinib approved by the FDA, but it was reported to have a narrow therapeutic window for EGFR ${ }^{\mathrm{WT}}$ and $\mathrm{EGFR}^{\mathrm{T} 790 \mathrm{M}}$ patients, which leads to side effects on normal tissues $(14,25,60)$. Combinational therapy has also largely been investigated to overcome resistance; however, until now, the efficacy of multiple targeting in clinical trials remained unknown and valid biomarkers for rational combination protocols are insufficient (24). Recently, thirdgeneration TKIs with a wider therapeutic window and efficacy to $\operatorname{EGFR}^{\mathrm{T} 790 \mathrm{M}}$ are currently being developed $(9,26)$; however, ultimate drug resistance could not be avoided without comprehensive investigation of resistance mechanism and complete $\mathrm{EGFR}^{\mathrm{T} 790 \mathrm{M}}$ elimination.

Although the precise mechanism of resistance remains unclear, reactive oxygen species (ROS) are heavily involved in cancer initiation and regulation by low-dose environmental pollutants (16), while the modulation of oxidative stress is recently proposed as a promising strategy for cancer therapy $(17,55)$. Cancer cells frequently exhibit high basal ROS levels due to oncogene activation and the loss of tumor suppressors, as well as a higher rate of cellular metabolism induced by the Warburg effect $(6,18)$; Therefore, ROS plays an important role in tumor initiation and progression and should be suppressed. However, the role of ROS in cancer cells is dual. For example, oppositely, the small-molecule piperlongumine was reported to selectively kill cancer cells by elevating the ROS level using dichlorofluorescein diacetate (DCFDA) staining detection $(33,39)$. This elevated ROS leads to protein damage due to oxidation, while cancer cells counteract stress either by increasing their antioxidant defenses via ROS elimination (ROS scavengers) (17) or protein reduction for redox balance $(7,20)$.

A pioneer investigation of the oxidation effect of EGFR revealed that oxidation of the EGFR ${ }^{\mathrm{WT}}$ cysteine 797 (Cys ${ }^{797}$ ) residue could enhance EGFR ${ }^{\mathrm{WT}}$ binding with NADPH oxidase isoform 2 (NOX2), leading to ROS generation and further EGFR activation $(13,37,56)$; however, to our knowledge, the oxidation effect on EGFR mutant and its biological effect in a cancer model have not been investigated. Together, ROS properties and their regulatory mechanisms by NOX isoforms (NOX1-5) remain unknown in gefitinib-resistant EGFR ${ }^{\mathrm{T} 790 \mathrm{M}}$ cells. Additionally, determining the oxidative effect, the threshold to resist oxidative damage, and the redox balancing capacity of EGFR ${ }^{\mathrm{WT}}$ and $\mathrm{EGFR}^{\mathrm{T} 790 \mathrm{M}}$ mutants is required for overcoming such acquired resistance.

In this study, we hypothesized that the half-lives of $\mathrm{EGFR}^{\mathrm{T} 790 \mathrm{M}}$ mutant and EGFR ${ }^{\mathrm{WT}}$ are different and are closely associated with intracellular ROS level and oxidation capacity. We have also proposed a new specific therapeutic targeting strategy for this subgroup of EGFR ${ }^{\mathrm{T} 790 \mathrm{M}}$ mutant patients by manipulating the redox balance and protein oxidation. We have also proposed a new biomarker for this subgroup of patients for better personalized medicine decision.

\section{Results}

\section{Selectively killing gefitinib-resistant NSCLC cells by elevating the ROS level}

In this study, we have first examined the basal ROS levels and the ROS elevation effect on NSCLC, especially on NSCLC with EGFR ${ }^{\mathrm{T} 790 \mathrm{M}}$ mutation. Among the NSCLC cell line panels, we found that the gefitinib-resistant cell lines, H1975 (36) and H820 (2), which harbor additional

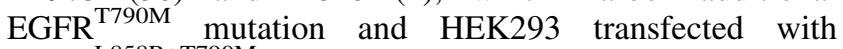
EGFR $^{\text {L858R+T790M }}$, showed higher basal ROS levels than cell lines with EGFR ${ }^{\mathrm{WT}}$ and EGFR single mutation (Fig. 1A, B). To further examine the role of ROS level in cancer cells, a small molecule, sanguinarine, which was reported to quickly elevate the ROS level (31), was employed in this study. Interestingly, sanguinarine induced substantially stronger cytotoxicity and apoptosis in H1975 and H820 cells compared with other cell lines (Fig. 1C), but is relatively safe for normal lung cell CCD-19Lu (Supplementary Fig. S1; Supplementary Data are available online at www.liebertpub.com/ars). To further quantitatively measure levels of apoptosis induction, cells were stained with Annexin V/propidium iodide (PI) and the percentage of apoptotic cells was measured with a flow cytometer. After drug treatment, $35.5 \% \pm 11.6 \%$ of apoptosis was induced by sanguinarine treatment at $1.25 \mu \mathrm{M}$ when compared with $9.6 \% \pm 2.7 \%$ of basal apoptosis in H1975. Suppression of protein kinase B (AKT) and induction of poly ADP ribose polymerase (PARP) cleavage were observed, suggesting inhibition of the antiapoptotic pathway (Fig. 1D). To examine the downstream apoptotic pathway, JNK inhibitor was used. The JNK inhibitor only abolished the apoptotic effect of sanguinarine in A549, indicating that the induction of apoptosis in H1975 is independent of the JNK pathways (Fig. 1E), and there is a new and specific apoptosis mechanism that happened specifically on H1975 against A549.

\section{High basal ROS in NSCLC cells and clinical tumors}

To explore the underlying causes of high basal ROS in cancer cells, we examined the expression levels of the NOX family among three representative cell lines, A549 has EGFR $^{\text {WT }}$, HCC827 has single EGFR mutation, and H1975 has EGFR ${ }^{\mathrm{L} 858 \mathrm{R}+\mathrm{T} 790 \mathrm{M}}$ double mutation, and compared them with the data with CCD-19Lu normal lung fibroblast cell line using quantitative real-time polymerase chain reaction 
(Q-PCR). Results showed that among the five NOX isoforms, NOX2 has the highest expression levels and it also showed significantly higher expression than normal lung CCD-19Lu cells (Fig. 2A), while other NOX isoforms were found to be expressed in low or undetectable levels with NOX3 the lowest (Ct value 40; data not shown). Therefore, we further examined and compared both NOX2 and NOX3 expression in clinical lung tumors with their pair-up normal lung tissues due to such a big difference in expression pattern of these two NOX isoforms in cell lines. Similar to cell line data, Q-PCR analysis of clinical tumors revealed that NOX2 showed higher expression in 63 NSCLC tumors than 61 normal lung tissues, whereas 3 of which are clinical tumors with
EGFR $^{\mathrm{T} 790 \mathrm{M}}$ mutation also showed an average of around 4.49-fold higher than normal (Fig. 2B); Moreover, 60 NSCLC tumors were chosen to investigate the association between NOX2 and the prognosis of patients. Thirty patients with high NOX2 expression level have shorter progress-free survival time $(p=0.012)$ and marginal shorter overall survival time ( $p=0.054)$, indicating that the survival rate of patients in the high NOX2 group is much lower compared with the low NOX2 expression group (Fig. 2C, D). Similar to cell line data, NOX3 was not detected from all clinical tissues $(\mathrm{Ct}>40$ or undetectable, indicating no or low mRNA expression levels), suggesting the basal ROS that were generated by the NOX family in cancer cell
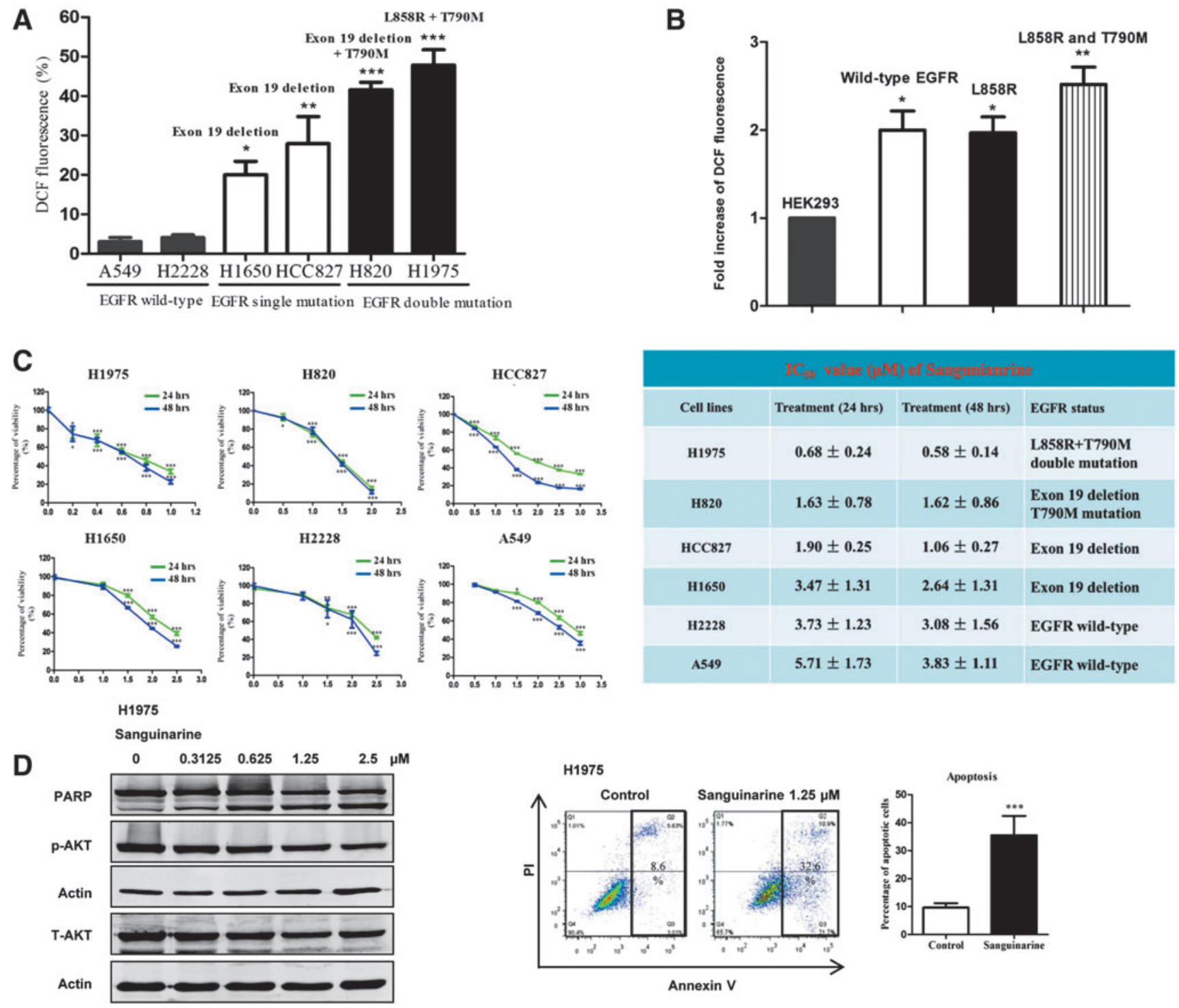

FIG. 1. High basal ROS levels in NSCLC cell lines and the selective killing effect of sanguinarine on NSCLC cells with EGFR T790M. (A) Comparison of the basal ROS levels across a panel of NSCLC cell lines and transfected cell lines presented as a bar chart $(* p<0.05 ; * *<<0.01 ; * * *<0.001)$. (B) HEK293 transfected with EGFR ${ }^{\mathrm{L} 858 \mathrm{R}+\mathrm{T} 790 \mathrm{M}}$ showed higher basal ROS levels than cells overexpressed with EGFR ${ }^{\mathrm{WT}}$ and EGFR single mutation. (C) The $\mathrm{IC}_{50}$ value of sanguinarine in six NSCLC cell lines $(* p<0.05$; *** $p<0.001)$. (D) Flow cytometry and Western blot analysis of the apoptotic effect of sanguinarine in H1975 $(* * * p<0.001)$. Actin was used as a loading control. (E) Flow cytometry analysis of single treatment and cotreatment with sanguinarine and JNK inhibitors in $\mathrm{H} 1975$ and A549 $(* * p<0.01 ; * * * p<0.001)$. All experiments were performed at least thrice $(n=3)$. EGFR, epidermal growth factor receptor; NSCLC, non-small cell lung cancer; ROS, reactive oxygen species; WT, wildtype. To see this illustration in color, the reader is referred to the web version of this article at www.liebertpub.com/ars 
E

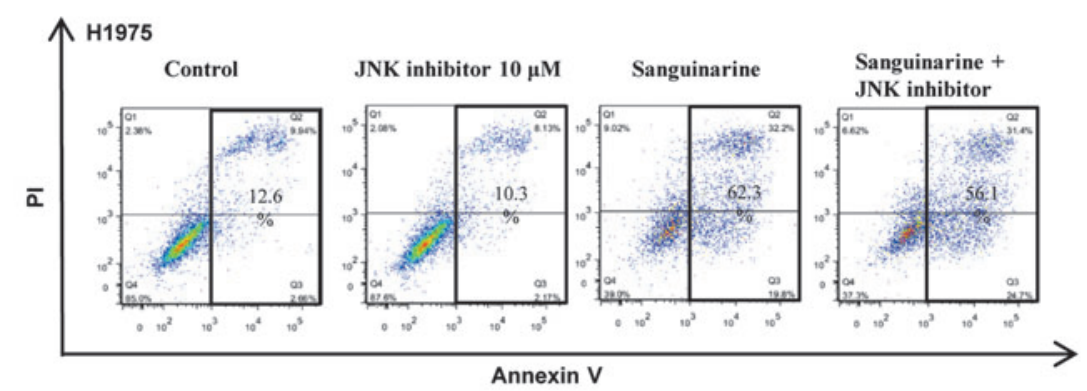

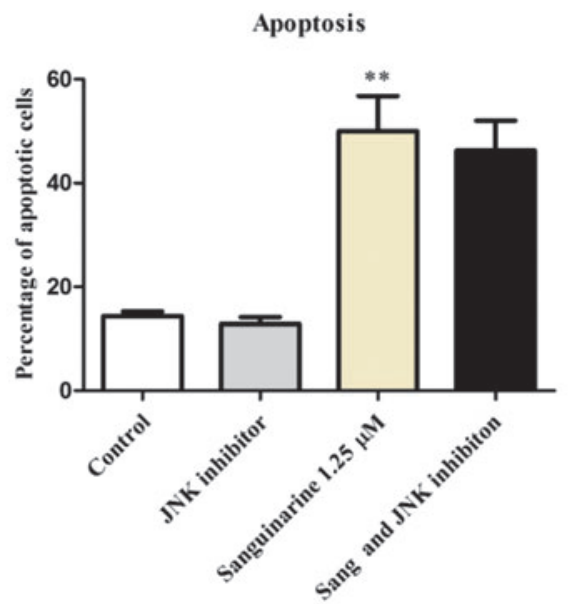

Apoptosis

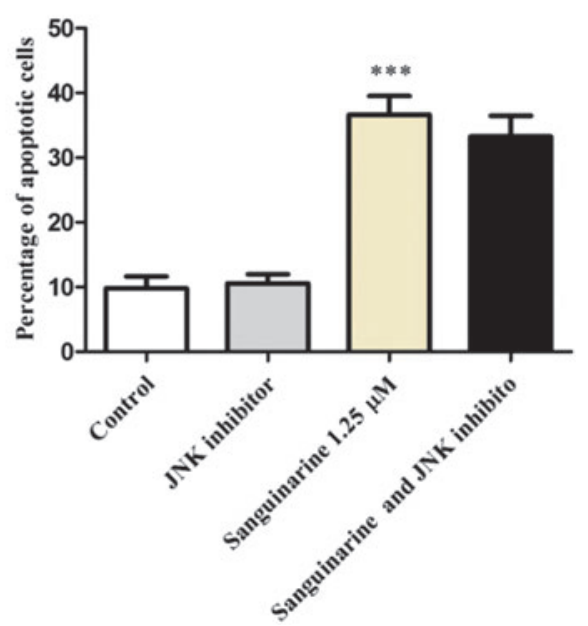

FIG. 1. (Continued)

lines and clinical tumors correlated with NOX2 overexpression, but not NOX3.

\section{Selectively inducing EGFR ${ }^{\text {T790M }}$ degradation by ROS elevation}

To further examine the effect of ROS elevation and identify the types of ROS release, we further measured ROS with the specific detection kit and correlated the changes with biochemical effect on EGFR. ROS were remarkably increased starting at $30 \mathrm{~min}$, suggesting that sanguinarine quickly initiated ROS directly after treatment (Fig. 3A). To confirm the source of ROS elevation, we detected the types of ROS generated using a kit specific to superoxide $\left(\mathrm{O}_{2}^{-}\right)$; the result showed that most of the elevated ROS species were $\mathrm{O}_{2}{ }^{-}$, which was the product of NADPH oxidases (NOXs) (Fig. 3A), suggesting that sanguinarine had activated NOXs to generate $\mathrm{O}_{2}^{-}$. Interestingly, ROS elevation specifically induced cbl-mediated EGFR degradation in NSCLC cells with EGFR ${ }^{\mathrm{T} 790 \mathrm{M}}$ (Fig. 3B), resulting in shutdown of EGFR downstream proliferation and antiapoptotic signaling. Importantly, neither afatinib nor the first-line lung cancer chemo-drug, cisplatin, induced EGFR degradation in H1975 gefitinib-resistant cell, although the ROS level was mildly elevated by afatinib, but not cisplatin (Figs. 3B and 5B), indicating that elevating ROS by sanguinarine (and most likely other small molecules) represents a new strategy for overcoming gefitinib resistance. Blocking ROS using N-acetyl-1cysteine (NAC) and proteasomal degradation pathway inhibitor (MG132) significantly attenuated sanguinarine-induced EGFR degradation and apoptosis (Fig. 3C), indicating that ROS elevation is essential for the sanguinarine-induced apoptosis of H1975 mediated by EGFR proteasomal degradation. Additionally, the apoptotic effect was mediated through mitochondria disruption (Fig. 3D), EGFR internalization (Fig. 3E), and caspase activation (Fig. 4A, B).

To confirm whether specific and inductive EGFR ${ }^{\mathrm{T} 790 \mathrm{M}}$ degradation effect of sanguinarine is due to the individual characteristics of H1975 and H820, we further transfected WT, multiple common single and double EGFR mutant constructs into HEK293 cells. Interestingly, only the T790Mcontaining transfectants, both single mutant and those coupled with mutation partners, responded to sanguinarine-induced EGFR degradation and apoptosis (Fig. 4C), suggesting that the presence of T790M mutation on EGFR is a determinant of ROS-mediated EGFR degradation. Moreover, EGFR degradation was only induced by sanguinarine in NSCLC cells with $\mathrm{EGFR}^{\mathrm{L} 858 \mathrm{R}+\mathrm{T} 790 \mathrm{M}}$ in a dose-dependent manner, which did not happen in the case for NSCLC cells with EGFR ${ }^{\text {WT }}$ 


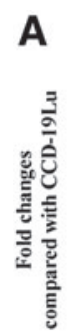

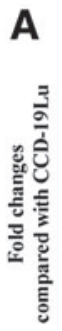

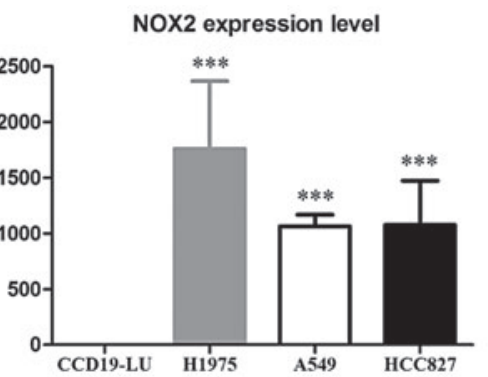

C

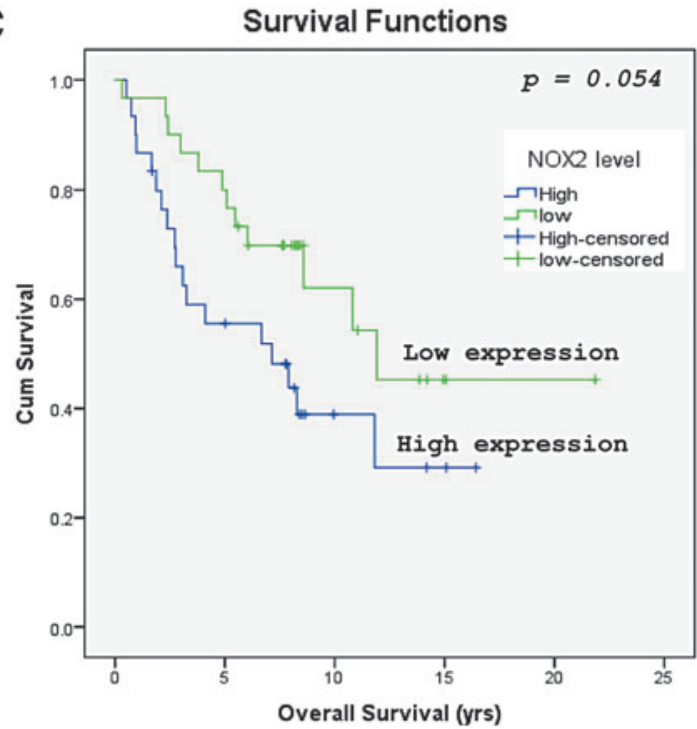

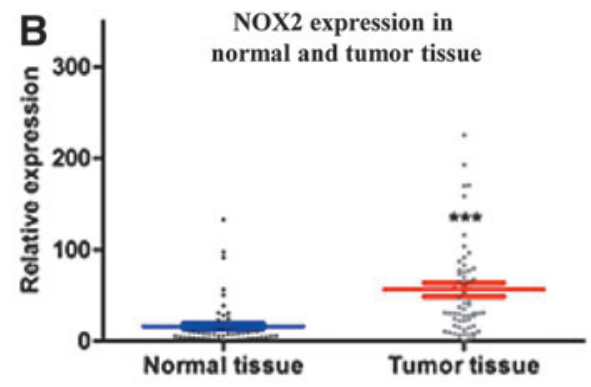
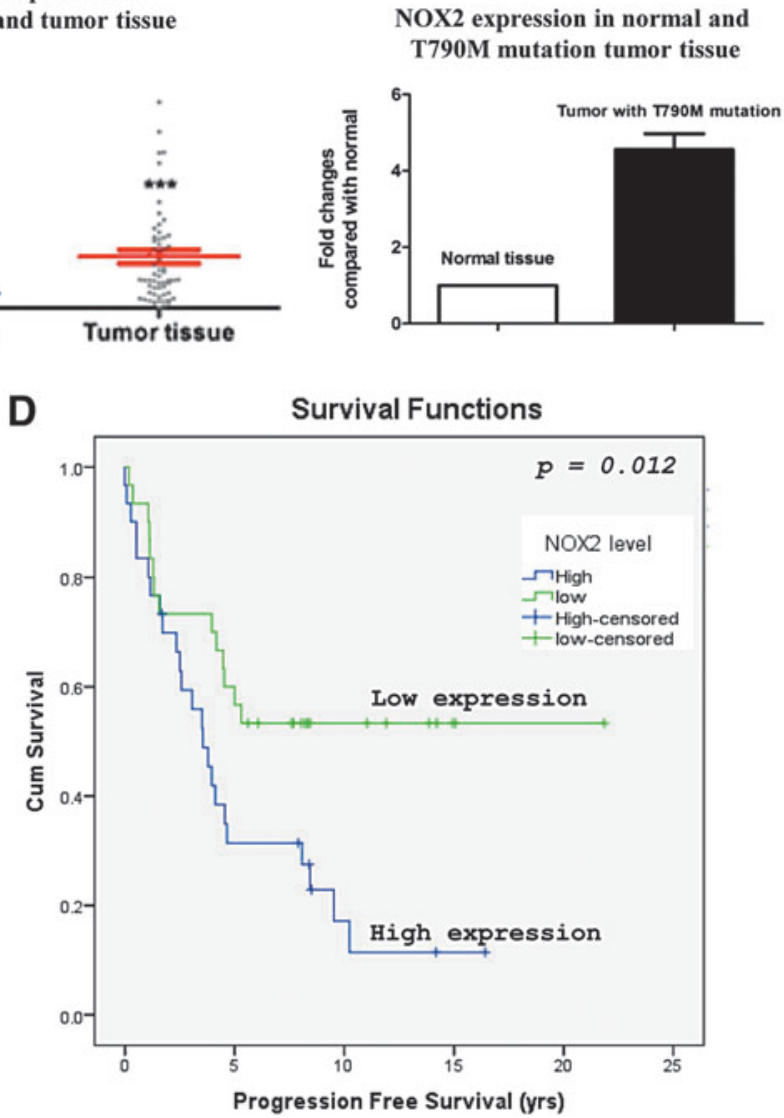

FIG. 2. The expression level of NOX2 in NSCLC cell lines and NSCLC patients was significantly higher. (A) Q-PCR analysis showed that NOX2 was highly expressed in NSCLC cell lines than normal lung CCD-19Lu fibroblast cell line. (B) Q-PCR analysis showed that NOX2 expression in 63 clinical lung tumor is much higher compared with 61 normal tissues $(* * * p<0.001)$. NOX2 is also highly expressed in tumor tissue with T790M mutation than normal tissue. (C, D) The association between NOX2 and the prognosis of patients $(n=60)$. The survival rate of patients in the high NOX2 group is also much lower compared with low NOX2 expression group. NOX2, NADPH oxidase isoform 2; Q-PCR = quantitative real-time polymerase chain reaction. To see this illustration in color, the reader is referred to the web version of this article at www.liebertpub.com/ars

(Fig. 4D). Hydrogen peroxide $\left(\mathrm{H}_{2} \mathrm{O}_{2}\right)$ is a species of ROS and therefore it was used to further confirm whether ROS elevation is involved in EGFR degradation induction (Fig. 4D). Distinct responses of EGFR were revealed in H1975 with the activation of Y1045, which leads to activation of cblmediated EGFR internalization, and deactivation of Y845 and Y1068 of EGFR, which leads to shutdown of downstream cell survival signal, while in contrast, the maintenance of EGFR expression was observed in A549 (Fig. 4D), suggesting a distinct biological behavior and cell fate in response to ROS elevation between H1975 and A549.

\section{NOX3 upregulation by sanguinarine causing selective EGFR ${ }^{\text {T790M }}$ degradation}

Direct inhibition of superoxide dismutase 1 (SOD1) by small molecule, causing intracellular accumulation of $\mathrm{H}_{2} \mathrm{O}_{2}$, can also induce cell death on broad types of NSCLC cells with different mutational profiles; however, specific induction of cell death via EGFR $^{\mathrm{T} 790 \mathrm{M}}$ degradation was not achieved by increasing $\mathrm{H}_{2} \mathrm{O}_{2}$ alone $(15,49)$, suggesting that NOX3 plays an additional role in redox balancing rather than just elevating ROS in mediating the specific EGFR ${ }^{\mathrm{T} 790 \mathrm{M}}$ degradation effect.
Therefore, an array of molecular assays was performed to identify the drug action target of sanguinarine-mediated EGFR degradation. In the current study, we found that sanguinarine only upregulated NOX3, but not other NOXs (Fig. 5A), suggesting that NOX3 plays a central role in the sanguinarinemediated EGFR degradation and apoptosis of EGFR ${ }^{\mathrm{T} 790 \mathrm{M}}$ cells. Sanguinarine-mediated EGFR degradation and apoptosis were remarkably attenuated by NOX3 inactivation using NOX3 small interfering RNA (siRNA) (with nonspecific siRNA as control) or NOX inhibitor (diphenyleneiodonium [DPI]) (Fig. $5 \mathrm{~B}-\mathrm{D})$, indicating that NOX3 plays a crucial role in mediating the sanguinarine effect. Physiologically, methionine reductase A (MsrA) can use NADPH as the substrate to reduce the oxidized form of methionine back to the reduced form for protein protection $(7,20)$; therefore, under high basal ROS conditions, MsrA knockdown slightly weakened basal methionine protection (when compared with the nonspecific siRNA control), resulting in EGFR oxidation and degradation (Fig. 5D).

To investigate if EGFR is the direct target of sanguinarine, computational docking analysis was employed, and the docking data showed that sanguinarine had no selective binding to EGFR ${ }^{\mathrm{WT}}$ or $\mathrm{EGFR}^{\mathrm{T} 790 \mathrm{M}}$ (Fig. 6A); thus, the difference in cell responses to sanguinarine by direct drug 
binding on $\mathrm{EGFR}^{\mathrm{T} 790 \mathrm{M}}$ is unlikely, but indirectly caused by NOX3 upregulation. Under sanguinarine treatment condition, NOX3 oxidized NADPH, causing severe NADPH depletion and increase in $\mathrm{NADP}^{+} / \mathrm{NADPH}$ ratio (Fig. 6B) and eventual MsrA inactivation (19). To further confirm that apoptosis was induced by NOX3 activation and MsrA inactivation, we cotreated H1975 with sanguinarine and NADPH; we found that NADPH supplement attenuated the EGFR degradation and apoptotic effect of sanguinarine (Fig. 6C). Based on biochemical properties of the structure of these two amino acids, methionine and cysteine have a particular tendency to oxidize due to the presence of the sulfur atom $(4,7$, 56). To further examine whether the methionine of EGFR $^{\mathrm{T} 790 \mathrm{M}}$ has a high tendency to be locally oxidized by ROS, we investigated a short synthetic amino acid peptide corresponding to the EGFR ${ }^{\mathrm{T} 790 \mathrm{M}}$ mutant from amino acid position 788-792 (LIMQL) that contains a mutant methionine amino acid; we treated the synthetic peptide with both sanguinarine and $\mathrm{H}_{2} \mathrm{O}_{2}$ to induce oxidation. Mass spectrometry (MS) data showed that methionine 790 (M790) was specifically oxidized after treatment with $\mathrm{H}_{2} \mathrm{O}_{2}$ (but not sanguinarine) in a dose-dependent manner (Fig. 7A), indicating that sanguinarine-mediated ROS elevation relies on NOX3-induced ROS. A presynthesized (LIM(O)QL) oxidized form of methionine peptide was used as the MS standard of reference of the oxidized peptide form (Fig. 7A).

\section{In vivo study of the anticancer effect of sanguinarine}

To verify the in vivo effect of sanguinarine, H1975 xenograft using nude mice was tested by 32 days of intraperitoneal (i.p.) treatment with sanguinarine and the oral administration of afatinib. Compared with untreated animals, the tumor size in the sanguinarine-treated mice $(5 \mathrm{mg} / \mathrm{kg})$ showed a suppressive trend starting at day $22(25 \%)$ and significant suppression (40\%) at day 26; the suppressive potency was similar to that of afatinib (5 mg/ $\mathrm{kg}$ ) (Fig. 7B). The net tumor weight of sanguinarine-treated mice was significantly lower than the nontreated animals (Fig. 7C). Western blot of mouse tumor protein lysate showed NOX3 upregulation and EGFR downregulation, but no change of NOX2 after sanguinarine treatment. However, EGFR downregulation was not induced by afatinib, confirming the specific role of NOX3 in inducing EGFR degradation in response to sanguinarine and specific drug action of sanguinarine (Fig. 7D).

\section{Discussion}

The role of ROS in cancer has been discussed controversially; it has been long understood that antioxidants are beneficial in cancer prevention (1), while recent new hypothesis and data suggest that insufficient ROS can lead to complex diseases, for example, cancer and diabetes $(32,44$, 57). Overall, it seems that a valid biomarker is indeed needed to provide clues for making a rational decision on ROS elevation or suppression in cancer therapy. Furthermore, the role of ROS in specific subtype of TKI-resistant NSCLC also needs to be clearly clarified.

In the current study, we have first reported the role of ROS in TKI-resistant NSCLC, we found particularly high basal ROS levels in TKI-resistant NSCLC cell lines, and association of high NOX2 expression levels with poor patient survival in clinical lung tumors. Based on these clinical evidences, we hypothesized and reported a new specific targeting treatment strategy and treatment mechanism for this subgroup of TKI-resistant NSCLC patients with EGFR ${ }^{\mathrm{T} 790 \mathrm{M}}$ additional mutation, which represents almost half of all NSCLC TKI resistance cases. By using small-molecule sanguinarine to induce redox imbalance between NOX3 and MsrA and based on the specific weak protein oxidation protection capacity of EGFR ${ }^{\mathrm{T} 790 \mathrm{M}}$ characteristics, we are able to specifically induce $\mathrm{EGFR}^{\mathrm{T} 790 \mathrm{M}}$ degradation and apoptosis. Furthermore, we have also verified the role of basal and elevated levels of ROS in this subtype of lung cancer and have validated the findings using a mouse model. Sanguinarine has been previously shown to induce apoptosis in lung cancer via glutathione depletion using the A549 cell line, which has wild-type (WT) EGFR (22), or it can act as an inhibitor of VEGF $(12,58)$. However, its clinical utility has been described as limited due to the nonselective anticancer effect (10). However, in this study, we have found a new alterative role of sanguinarine, which can selectively and effectively target NSCLC with EGFR ${ }^{\mathrm{T} 790 \mathrm{M}}$ mutation, with a different treatment mechanism from the previously reported literature.

Conventionally, EGFR degradation is a physiological protein recycling mechanism triggered by first EGF stimulation, followed by activation of EGFR Y1045 phosphorylation site and docking of cbl, and then EGFR internalization via the proteosomal degradation pathway $(45,47,53)$. However, biochemical studies on the clinically reported common EGFR mutants found in NSCLC patients revealed that these common EGFR mutations are activating mutation, which leads to constitutive activation of EGFR signaling without the need of ligand binding, and plays a causative role in lung tumor initiation, progression, and maintenance $(30,50)$. Moreover, previous studies demonstrated that $\mathrm{EGFR}^{\mathrm{T} 790 \mathrm{M}}$ mutants exhibit prolonged half-life by defective dimerization with HER2, resulting in impaired EGFR ubiquitination

FIG. 3. Elevation of the ROS and specific induction of EGFR ${ }^{\mathrm{T} 790 M}$ degradation are essential to mediate sanguinarineinduced apoptosis. (A) Flow cytometry quantitative analysis of the ROS and superoxide levels in H1975 after sanguinarine treatment $(* * * p<0.001)$. (B) Sanguinarine-induced EGFR degradation was mediated by first activation of EGFR Y1045, followed by activation of cbl. Afatinib and cisplatin did not induce EGFR degradation even at dosage much higher than the $\mathrm{IC}_{50}$ value of sanguinarine. (C) Combined-use effect of sanguinarine and NAC or MG132 in H1975 and selective EGFR degradation induction effect by sanguinarine in H1975. (D) Sanguinarine induced mitochondria disruption. Flow cytometry data showed that the mitochondrial membrane potential was lost after treatment with sanguinarine. Western blot results showed that sanguinarine treatment slightly increased Bax, while significantly decreasing Bcl-2 and Bcl-xl proteins in a dose-dependent manner, which resulted in a remarkable increase in the ratio of Bax/Bcl-2, leading to mitochondrial disruption. (E) Image of EGFR IF of H1975 after sanguinarine treatment. EGFR internationalization is indicated by a red arrow. The green fluorescence represents the EGFR immunofluorescence signal. All experiments were performed at least thrice $(n=3)$. IF, immunofluorescence; NAC, N-acetyl-1cysteine. To see this illustration in color, the reader is referred to the web version of this article at www.liebertpub.com/ars 
and lysosomal degradation, thus maintaining downstream EGFR survival signaling (48). Therefore, specifically inducing $\mathrm{EGFR}^{\mathrm{T} 790 \mathrm{M}}$ degradation would be a promising strategy for developing fourth-generation TKIs to overcome gefitinib resistance that is related to acquiring $\mathrm{EGFR}^{\mathrm{T} 790 \mathrm{M}}$ additional mutation, and currently, there is no drug of this type clinically available yet. To date, although combined application of monoclonal antibody, cetuximab, and irreversible TKI, afatinib, was previously shown to be able to inhibit both EGFR phosphorylation and downregulate EGFR in vivo, the
A

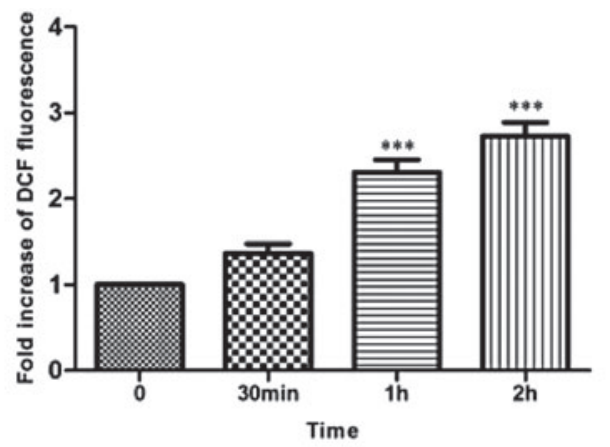

B

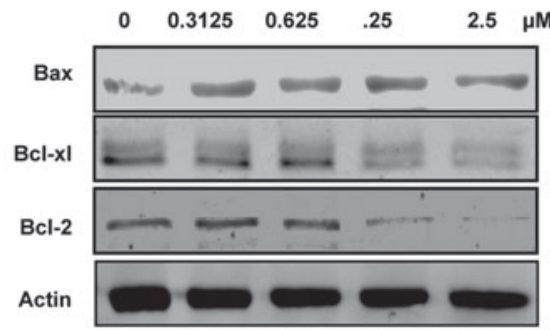

B Sanguinarine $1.25 \mu \mathrm{M}$

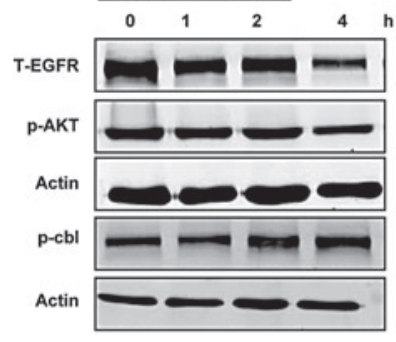

C

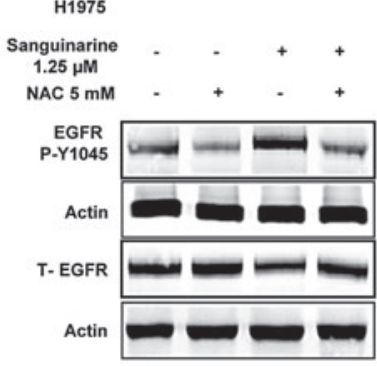

D

H1975 Sanguinarine

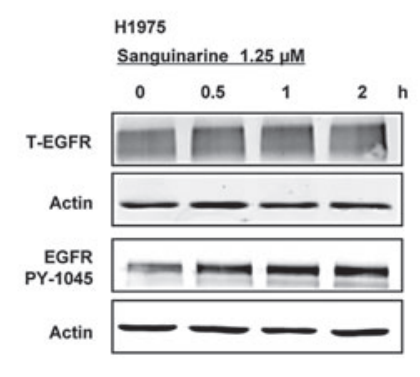

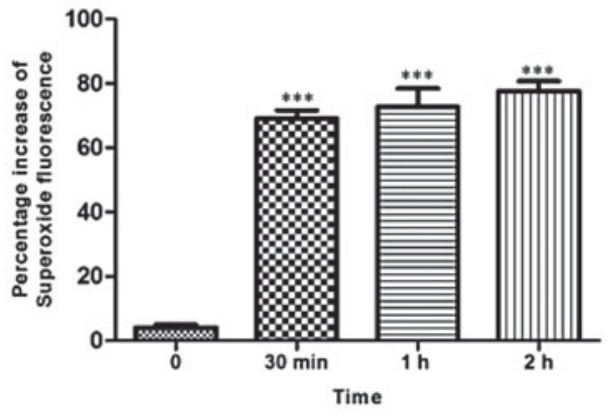

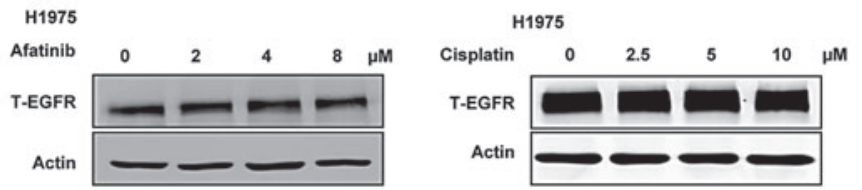

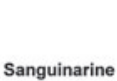

T-EGFR $\begin{array}{cccc}\text { H1975 } & \text { H1650 } & \text { A549 } & \text { HCC827 } \\ \text { (L858R+T790M) } & \text { (Exon19 deletion) } & \text { (EGFR wild-type) } & \text { (Exon19 deletion) }\end{array}$ - (Exon19 deletion) (EGFR wild-type) (Exon19 deletion)

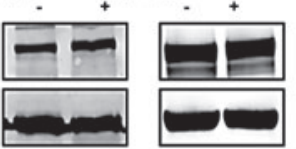

E

H1975

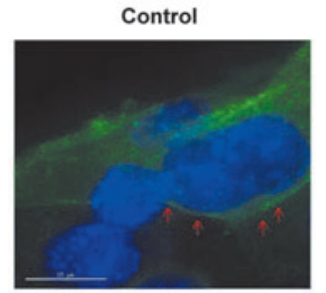

Sanguinarine $1.25 \mu \mathrm{M}$
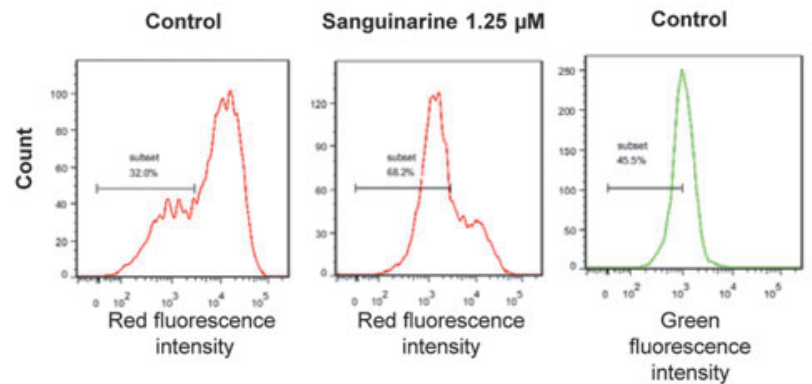

Sanguinarine $1.25 \mu \mathrm{M}$

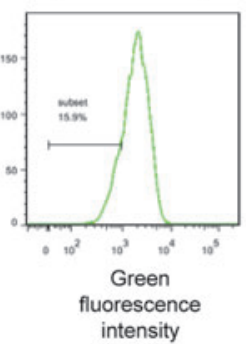


A

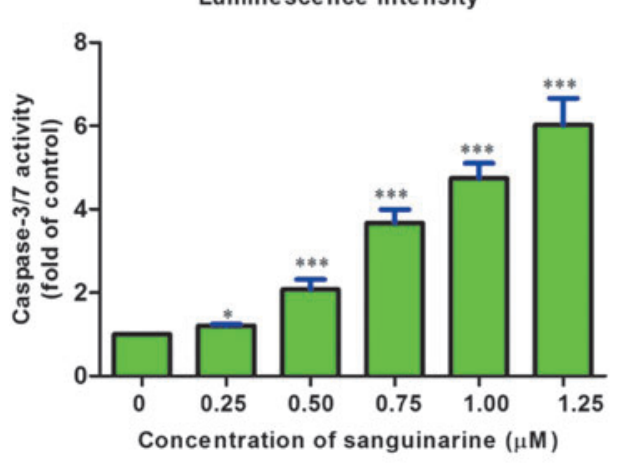

B
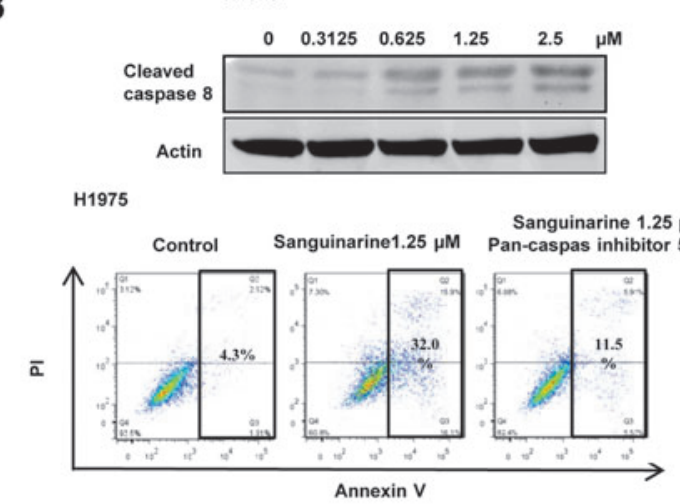

Annexin V
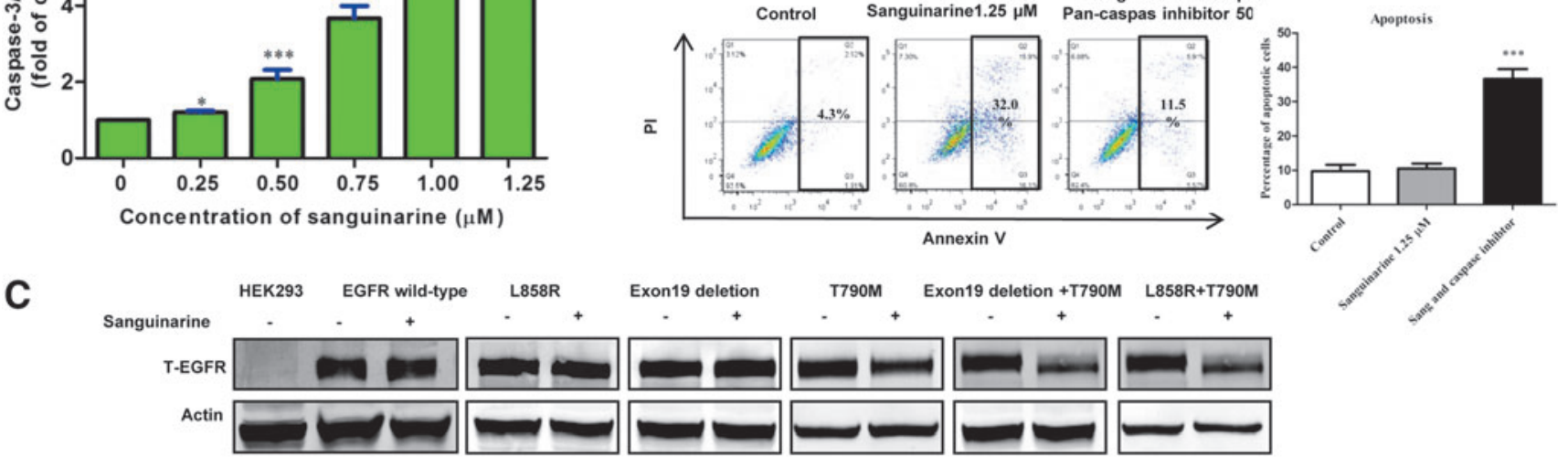

D
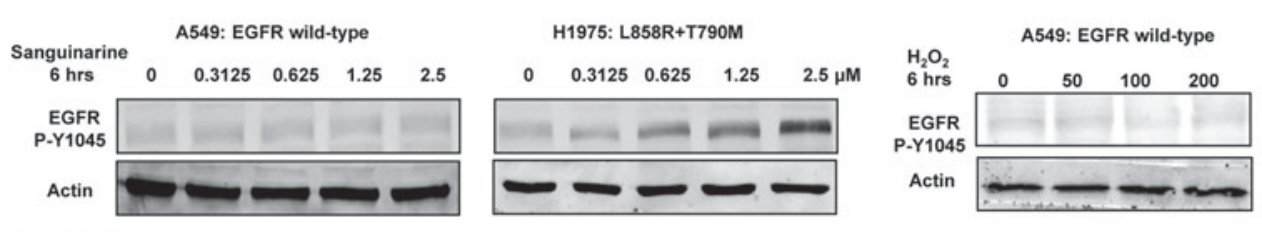

H1975: L858R+T790M
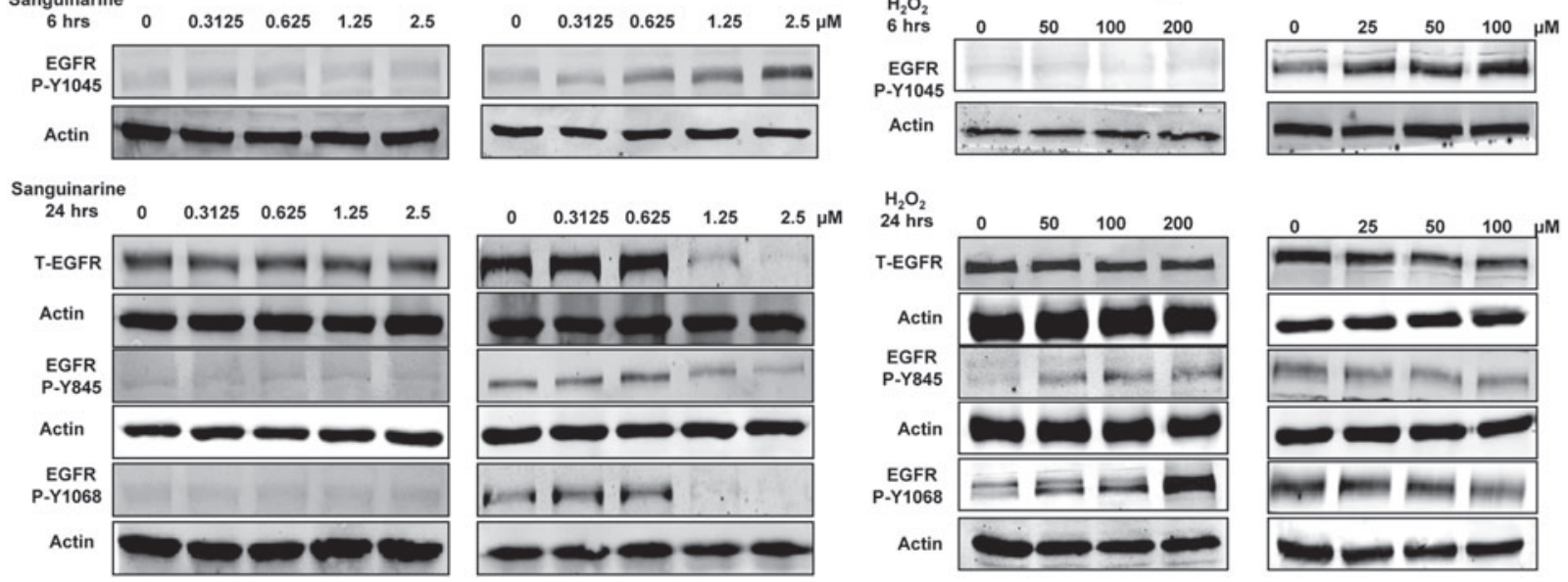

FIG. 4. Selective induction of EGFR degradation and apoptosis in gefitinib-resistant NSCLC with EGFR ${ }^{\text {T790M }}$. (A) Sanguinarine-mediated apoptosis is caspase dependent in H1975. Caspases-3/7 were activated by sanguinarine in a dosedependent manner $(* p<0.05 ; * * * p<0.001)$. (B) Caspase- 8 was activated by sanguinarine in a dose-dependent manner and pan-caspase inhibitor nearly completely blocked the apoptosis induced by sanguinarine $(* * * p<0.001)$. (C) Specific induction of EGFR degradation in HEK293 transfectants with EGFR ${ }^{\mathrm{T} 790 \mathrm{M}}$ constructs by sanguinarine. (D) The effect of ROS elevation by sanguinarine and $\mathrm{H}_{2} \mathrm{O}_{2}$ on both EGFR ${ }^{\mathrm{T} 790 \mathrm{M}}$ and EGFR ${ }^{\mathrm{WT}}$ cells. The phosphorylation of $\mathrm{Y} 1045$ was detected at $6 \mathrm{~h}$ after treatment, while phosphorylation of other sites on EGFR and total EGFR levels were detected at $24 \mathrm{~h}$. Actin was used as loading control. All experiments were performed at least thrice $(n=3)$. To see this illustration in color, the reader is referred to the web version of this article at www.liebertpub.com/ars

downregulation effect is not specific to $\mathrm{EGFR}^{\mathrm{T} 790 \mathrm{M}}$ and the mechanism still remains unknown (40). More importantly, such combined remedy is still unable to induce EGFR $^{\mathrm{T} 790 \mathrm{M}}$ protein degradation, thus gefitinib resistance is still unavoidable.
There is increasing evidence that ROS serves as a second messenger to mediate multiple signaling pathways and cellular responses, for example, $\mathrm{H}_{2} \mathrm{O}_{2}$ can exert reversibly redox regulation on protein tyrosine phosphatases, which act as housekeeping enzymes to reverse upstream kinase activity

FIG. 5. Sanguinarine induced apoptosis in gefitinib-resistant NSCLC with $\mathrm{EGFR}^{\mathrm{T} 790 \mathrm{M}}$ by upregulating and activating NOX3. (A)Western blot analysis of the effect of sanguinarine on EGFR ${ }^{\mathrm{T} 790 \mathrm{M}}$ and EGFR ${ }^{\mathrm{WT}}$ NSCLC cell lines (H1975, H820, A549, and H1650). (B) The ROS levels of control and drug treatment for $24 \mathrm{~h}$ in H1975 (***, ${ }^{+++}$, and \#\#\# $p<0.001$; gefitinib $10 \mu M$, afatinib $10 \mu M$, DPI $10 \mu M$, NAC $5 \mathrm{mM}$, cisplatin $10 \mu M$, sanguinarine $1.25 \mu M$, and $\mathrm{H}_{2} \mathrm{O}_{2}$ $100 \mu M$ ). (C) The effect of the NOX3 inhibitor (DPI) on sanguinarine treatment in H1975 $(* * * p<0.001)$. (D) The effect of NOX3 and MsrA knockdown at basal conditions and under sanguinarine treatment conditions in H1975. Actin was used as a loading control for all Western blot analysis $\left({ }^{*} p<0.05\right.$ and $\left.{ }^{*} p<0.01\right)$ All experiments were performed at least thrice $(n=3)$. DPI, diphenyleneiodonium; MsrA, methionine reductase A. To see this illustration in color, the reader is referred to the web version of this article at www.liebertpub.com/ars 
A

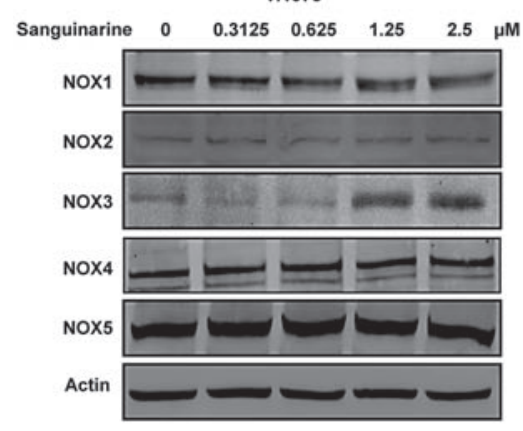

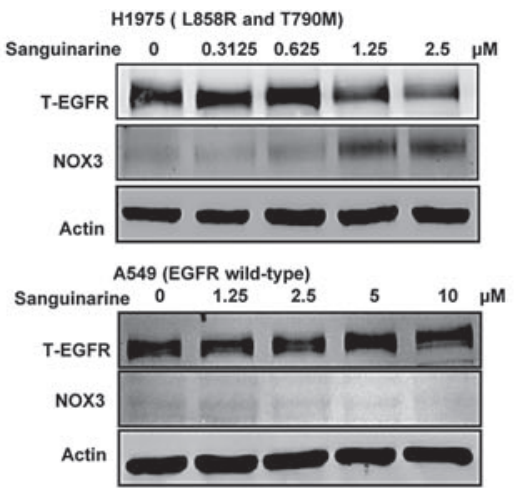

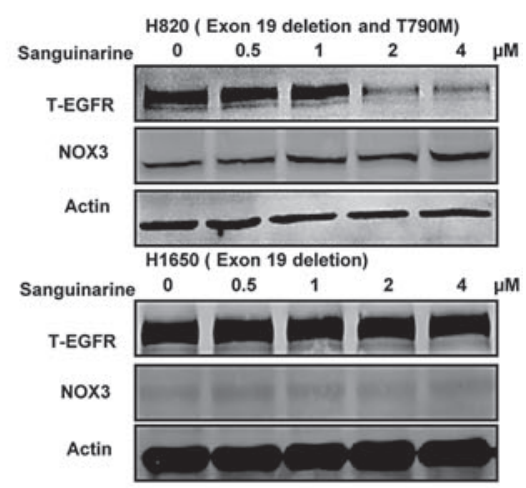

B

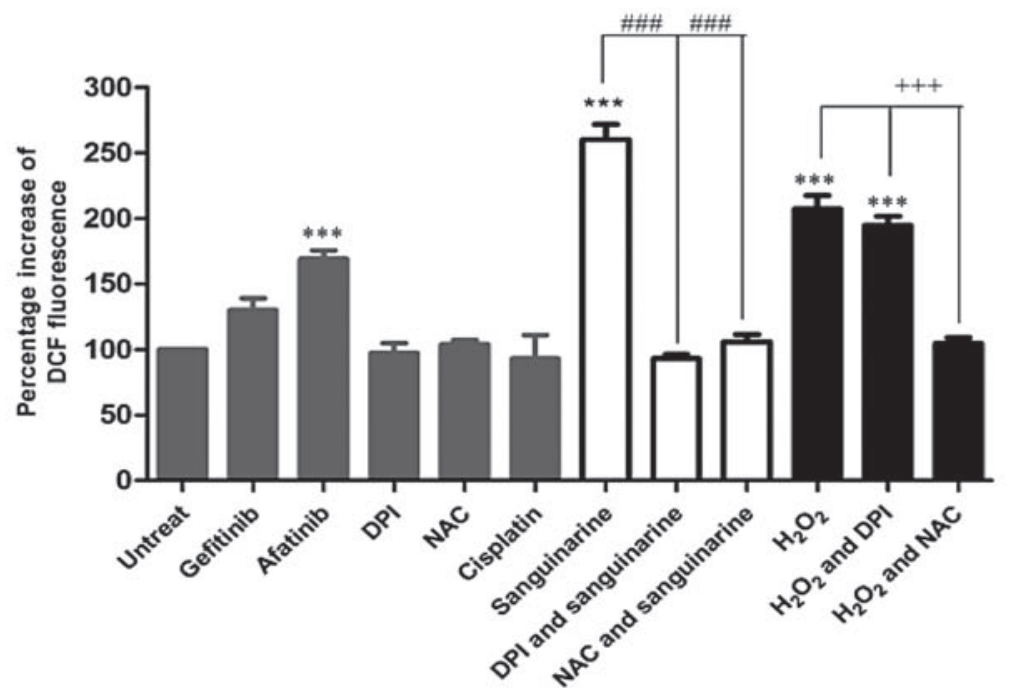

C
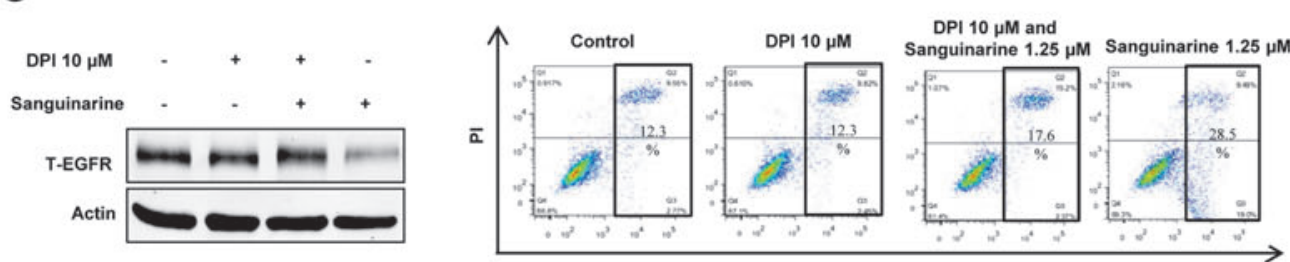

Annexin V

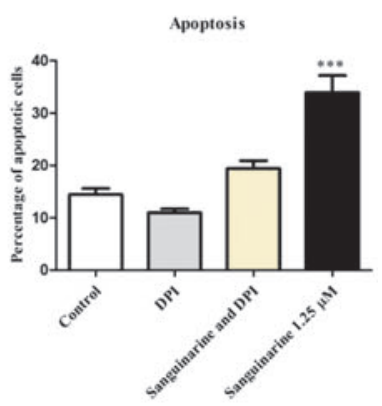

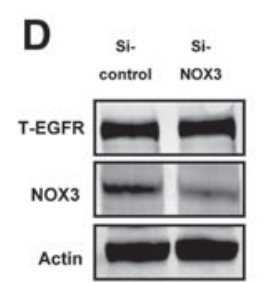

Control

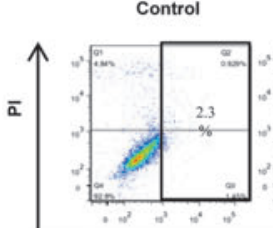

Si- Control

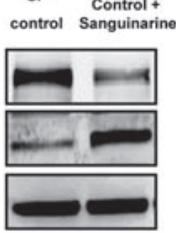

Si-control

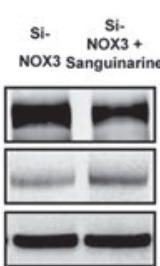

Si-NOX3

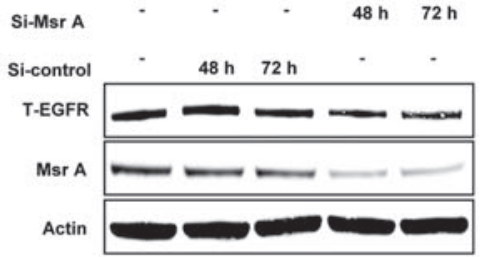

Sanguinarine

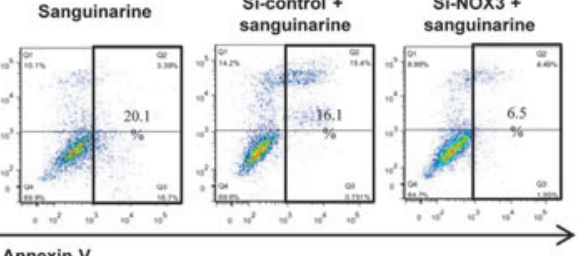

Annexin
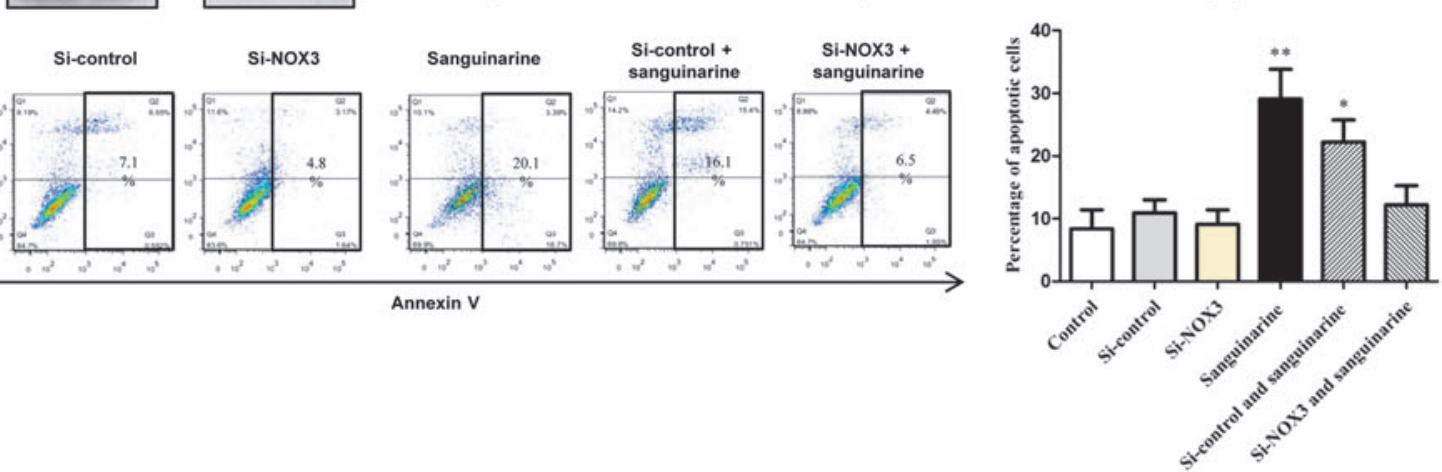

Apoptosis 
A
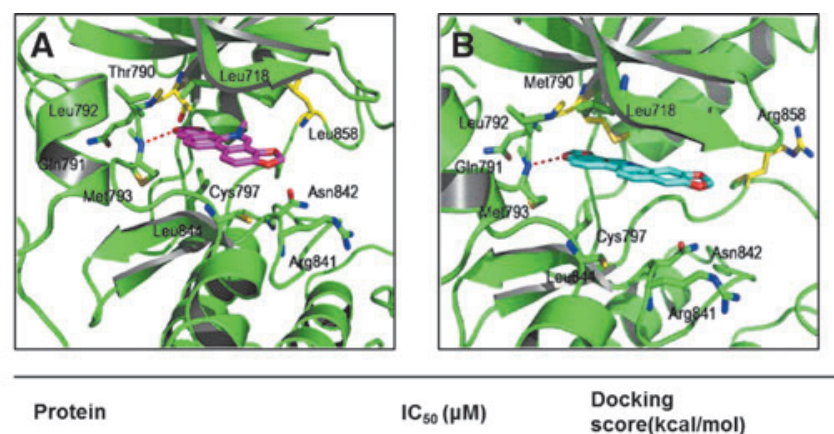

\begin{tabular}{lll}
$\mathrm{IC}_{50}(\mathrm{MM})$ & score(kcal/mol) \\
\hline
\end{tabular}

Wild-Type EGFR

5.71

$-6.40$

EGFR (T790M/L858R)

0.68

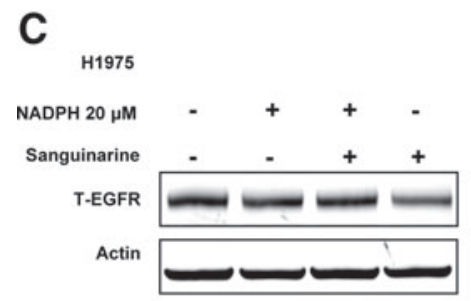

H1975

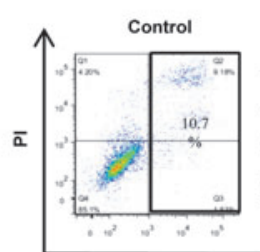

$-6.91$
B ${ }_{\text {H1975 }}$

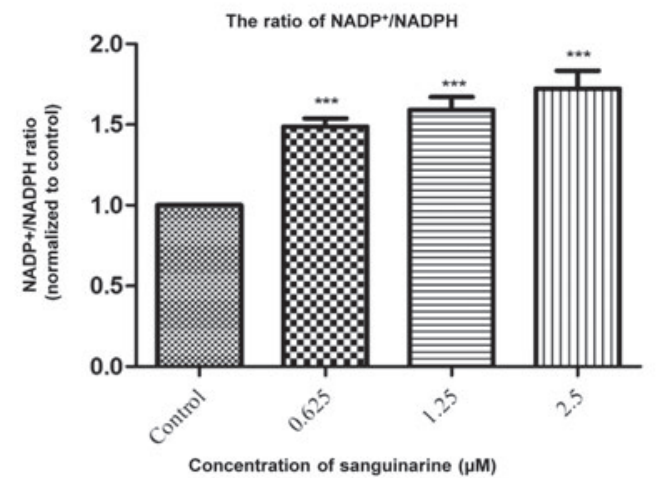

FIG. 6. Binding prediction of sanguinarine and depletion of NADPH by NOX3 is essential to mediate sanguinarineinduced apoptosis in H1975. (A) The binding mode of sanguinarine to WT EGFR and EGFR double mutant (T790M/L858R) crystalline structures obtained with a molecular docking calculation. (i) WT EGFR; (ii) EGFR double mutant (T790M/L858R). The proteins are represented with a green cartoon. Sanguinarine and the residues in the active site are represented as sticks. Hydrogen bonds are represented as red dashed lines. The docking score showed no difference between the EGFR ${ }^{\mathrm{WT}}(-6.40 \mathrm{kcal} / \mathrm{mol})$ and double mutant $(-6.91 \mathrm{kcal} / \mathrm{mol})$, suggesting that sanguinarine has no selectivity between EGFR ${ }^{\mathrm{WT}}$ and $\mathrm{EGFR}^{\mathrm{T} 790 \mathrm{M} / \mathrm{L} 858 \mathrm{R}}$. (B) NOX3 activation leads to NADPH depletion. An increase in the NADP $/ \mathrm{NADPH}$ ratio was observed after sanguinarine treatment, suggesting that NOX3 activation caused a significant increase in NADPH oxidation, which resulted in NADPH depletion $(* * * p<0.001)$. (C) The supplementation of NADPH attenuated sanguinarine-induced apoptosis and EGFR degradation. Actin was used as loading control for all Western blot experiments $(* * * p<0.001)$. All experiments were performed at least thrice $(n=3)$. To see this illustration in color, the reader is referred to the web version of this article at www.liebertpub.com/ars

$(38,43,51,52)$. Besides protein oxidation, other important protein modifications can also be mediated by gasotransmitters such as nitric oxide (NO) and hydrogen sulfide $\left(\mathrm{H}_{2} \mathrm{~S}\right)(11,23)$. In this study, we found that ROS not only acts as second messenger of a signaling pathway but it can also directly modulate EGFR kinase activity. Since methionine has a particular high oxidation tendency due to the presence of the sulfur atom $(4,7,56), \mathrm{EGFR}^{\mathrm{T} 790 \mathrm{M}}$ protein has lower oxidative capacity; based on this biochemical property, we have designed a targeting tool drug, sanguinarine, to induce elevation of ROS levels. Our study demonstrated that ROS elevation effectively induced oxidation on methionine residue of EGFR ${ }^{\mathrm{T} 790 \mathrm{M}}$ mutant and eventually led to excessive $\mathrm{EGFR}^{\mathrm{T} 790 \mathrm{M}}$ protein damage and degradation, while no effect was shown in EGFR ${ }^{\mathrm{WT}}$. Physiologically, NADPH is a critical modulator of cell redox state; under basal conditions, MsrA physiologically protects the M790 of EGFR from mild oxidative stress due to the presence of substrate NADPH, which can reduce the oxidized form of methionine back to the reduced form (54). When NOX3 is activated by small-molecule sanguinarine, it oxidizes NADPH and produces $\mathrm{H}_{2} \mathrm{O}_{2}$ (causing excessive ROS elevation and NADPH depletion that are beyond the theoretical threshold limit); MsrA inactivates due to lack of substrate NADPH, resulting in induction of redox imbalance between NOX3 and MsrA activity. As a result, methionine maintained oxidation due to insufficient reduction by MsrA, thus triggering EGFR overoxidation, degradation, oncogenic shock, and eventual apoptosis (Fig. 8A, B). These findings suggest that a novel treatment strategy could be formulated for T790M-associated gefitinib resistance via ROS elevation and redox imbalance between NOX3 and MsrA activity, while the T790M mutation is a valid biomarker of this condition. The induction of NOX3 activation and M790 oxidation is the optimal target for gefitinib-resistant T790Mpositive NSCLC cells. Notably, active NOX2 and NOX3 were reported to be localized at the plasma membrane where they have close proximity to EGFR $(5,34,37)$, which indicates high possibility of localized production of high concentration of ROS on the plasma membrane. However, the subcellular localization of active NOX3 and the exact roles of NOX3 should be further investigated and verified using multiple approaches, including those with patients and transgenic mice.

In conclusion, our findings provide profound insights into how to design a new class of EGFR-targeting therapeutics via 
A

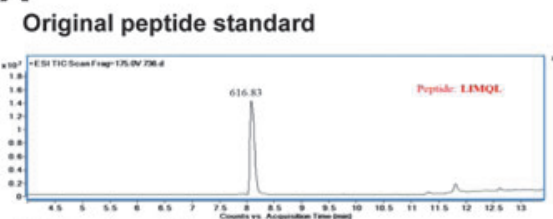

Oxidized peptide standard
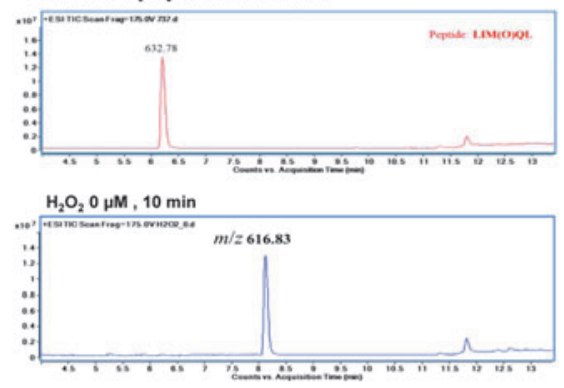

C

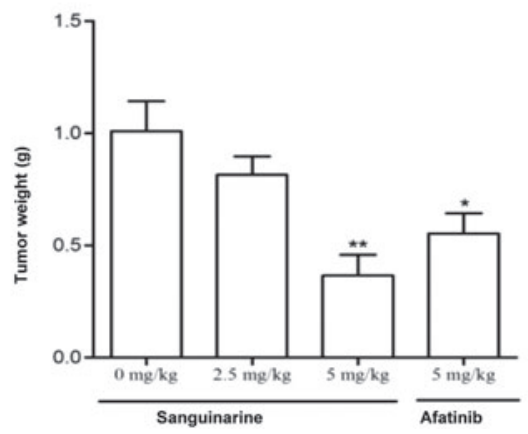

B

$\mathrm{H}_{2} \mathrm{O}_{2} 10 \mu \mathrm{M}, 10 \mathrm{~min}$

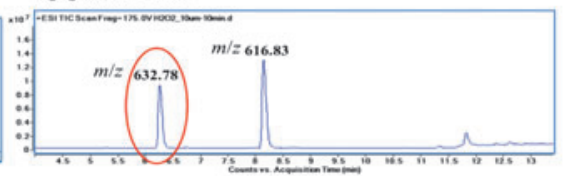

$\mathrm{H}_{2} \mathrm{O}_{2} 20 \mu \mathrm{M}, 10 \mathrm{~min}$
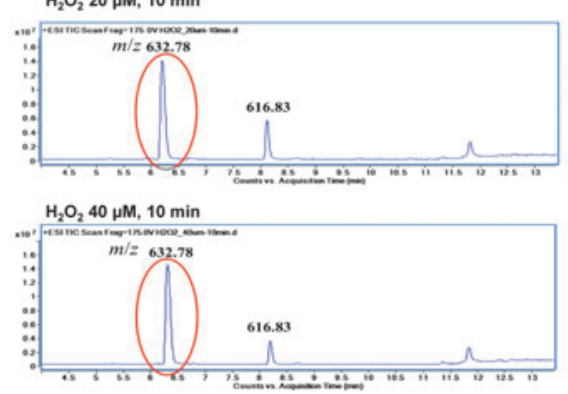

D
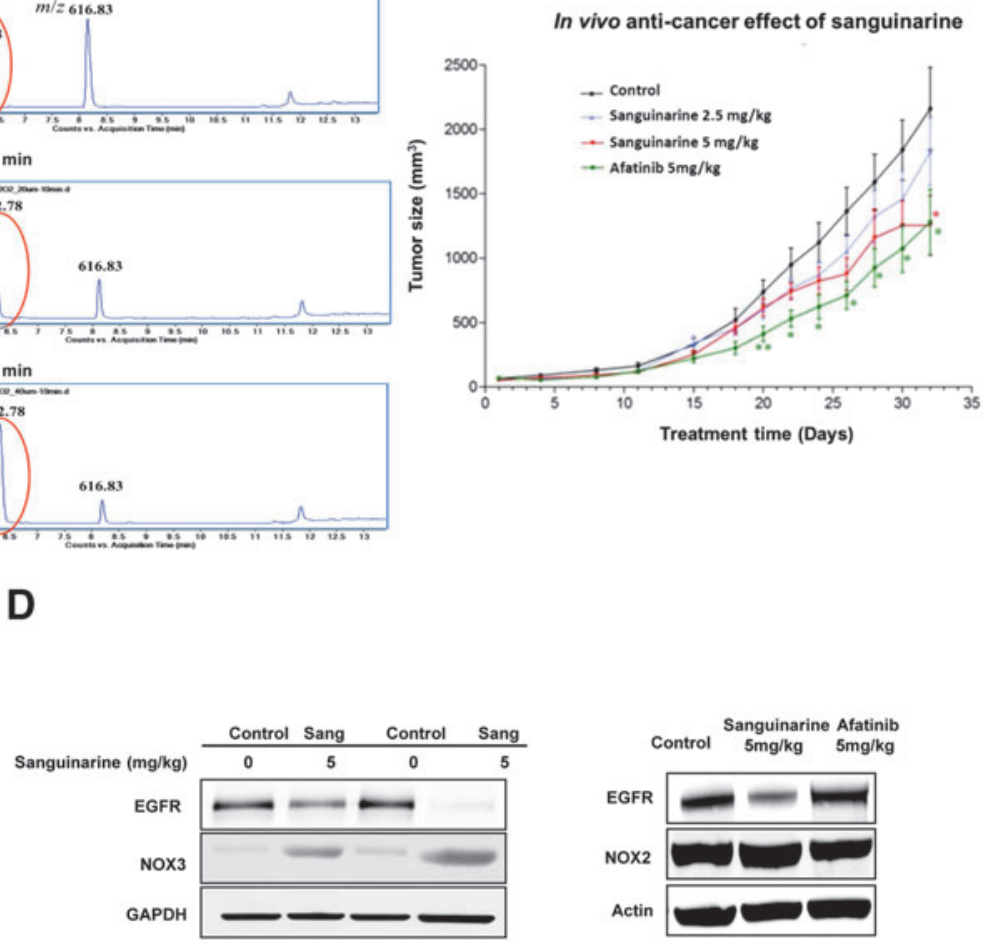

FIG. 7. MS analysis of methionine oxidation and in vivo antitumor effect of sanguinarine. (A) MS analysis of the molecular weight of the EGFR peptide before and after $\mathrm{H}_{2} \mathrm{O}_{2}$ treatment. Unoxidized and oxidized form peptides were synthesized and used as standards. The molecular weight of the unoxidized form peptide standard (LIMQL) is 616.83, while the oxidized form peptide standard (LIM $(\mathrm{O}) \mathrm{QL}$ ) is 632.78, analyzed by MS analysis. (B) Suppression of tumor growth of H1975 xenograft by sanguinarine and afatinib $(* p<0.05 ; * * p<0.01 ; n=10$ for each group). (C) Comparison of tumor net weight in sanguinarine and afatinib treatment groups with the control ${ }^{*} p<0.05 ; * * p<0.01 ; n=10$ for each group). (D) Western blot analysis of EGFR, NOX2, NOX3 protein expression on protein lysate of control, and drug-treated mouse tumors. Actin and GAPDH were used as loading control. All experiments were performed at least thrice $(n=3)$. MS, mass spectrometry. To see this illustration in color, the reader is referred to the web version of this article at www.liebertpub.com/ars

NOX3 and trigger redox imbalance between NOX3 and MsrA activity to induce EGFR degradation for gefitinibresistant patients, which advance translational research on personalized medicine and further global analysis in the redox proteomics of cancers (13). Our findings also provide a supplement to the current opinion of new drug development using small-molecule modulators of pro-oxidant or antioxidant pathways in cancer treatment (21).

\section{Materials and Methods}

\section{Materials}

Sanguinarine powder, NAC, and MG132 were purchased from Sigma-Aldrich (St. Louis, MO). Pan-caspase inhibitor, JC-1, and Annexin V/PI staining dye were purchased from BD Biosciences (Franklin Lakes, NJ). The specific NADPH oxidase (NOX) inhibitor DPI was purchased from Calbiochem (San Diego, CA). NADPH powder was purchased from Beyotime (Shanghai, China). A Caspase-GIo 3/7 Assay kit and NADP/NADPH-GIo ${ }^{\mathrm{TM}}$ assay kit were purchased from Promega (Madison, WI). Radioimmunoprecipitation assay (RIPA) lysis buffer (10x) and primary antibodies of actin, total
EGFR, phospho-845, phospho-1045 and phospho-1068 of EGFR, total/phospho-AKT, PARP, and cbl were purchased from Cell Signaling Technology (Danvers, MA). The primary antibodies of NOX1-5 were purchased from Sigma-Aldrich. The primary antibodies of Bcl-2, Bax, and MsrA were purchased from Santa Cruz (Dallas, TX). Fluorescein-conjugated goat anti-rabbit and mouse antibodies were purchased from Odyssey (Belfast, ME). ROS probe DCFDA staining, fetal bovine serum, $100 \mathrm{U} / \mathrm{mL}$ penicillin and $100 \mu \mathrm{g} / \mathrm{mL}$ streptomycin, Opti-MEM ${ }^{\circledR}$ I Reduced Serum Medium, Lipofectamine ${ }^{\mathrm{TM}}$ LTX Reagent, RNA extraction kit, and Prolong ${ }^{\circledR}$ Gold Anti-fade Reagent with DAPI were bought from Invitrogen (Carlsbad, CA). Superoxide detection kit was purchased from Enzo (Farmingdale, NY). Taq DNA Polymerase kit and cDNA synthesis kit were purchased from Roche (Basel, Switzerland). Plasmid extraction kit was purchased from Favogene (Ping-Tung, Taiwan).

\section{Cell lines and cell culture}

CCD-19Lu, A549, HCC827, H820, H1650, H1975, and H2228 were purchased from ATCC and cultivated with 

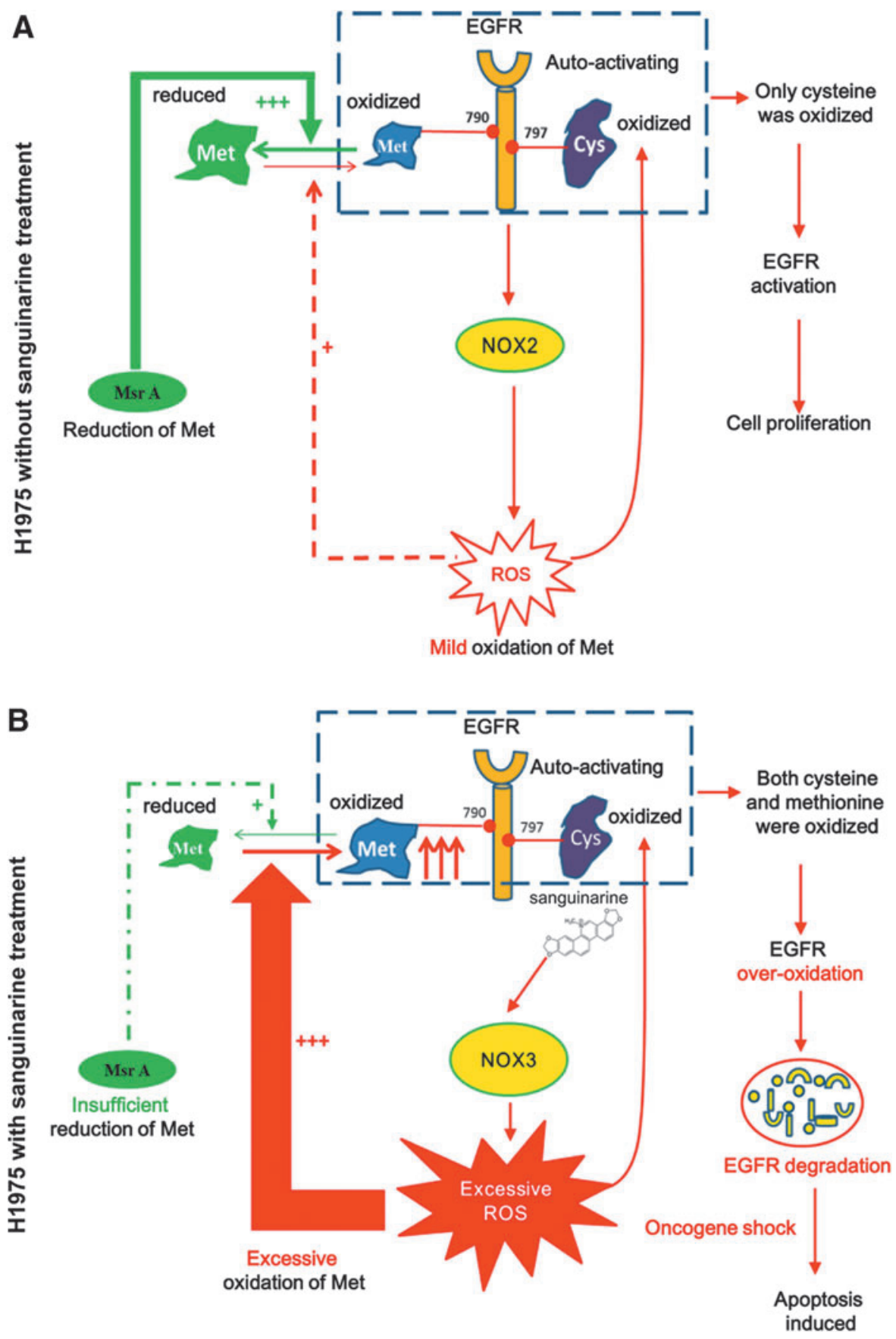

FIG. 8. Hypothetical cell model of basal and elevated ROS conditions on the fate of EGFR ${ }^{\mathrm{T} 790 \mathrm{M}}$. (A) At basal condition, active EGFR mutant oxidizes NOX2, elevates ROS, and further oxidizes EGFR $^{\text {Cysteiné797, }}$, resulting in mild oxidation of methionine on M790. However, basal activity of MsrA can reduce the oxidized form, methionine, back to the reduced form and protect it from degradation, resulting in cell survival. (B) Under treatment condition, sanguinarine triggers REDOX imbalance by activating NOX3, causing NADPH oxidation and depletion, resulting in MsrA inactivation and loss of protein reduction protection of the oxidized form, methionine, on M790 of EGFR. Accumulation of excessive amount of localized ROS induced $\mathrm{EGFR}^{\mathrm{T} 790 \mathrm{M}}$ overoxidation, degradation, shutdown of the EGFR downstream survival pathway, and induction of apoptosis. M790, methionine 790. To see this illustration in color, the reader is referred to the web version of this article at www.liebertpub.com/ars
RPMI 1640 medium supplemented with $10 \%$ fetal bovine serum, $100 \mathrm{U} / \mathrm{mL}$ penicillin, and $100 \mu \mathrm{g} / \mathrm{mL}$ streptomycin. All the cells were cultivated at $37^{\circ} \mathrm{C}$ with $5 \% \mathrm{CO}_{2}$ incubator. In the cotreatment experiments, the cells were pretreated with DPI, NAC, NADPH, and MG132 for $1 \mathrm{~h}$, and then cotreated with sanguinarine.

\section{MTT assay}

Cells were seeded on a 96-well microplate with 4000 cells/ well and cultured overnight for cell adhesion. Wide concentrations of the range of sanguinarine were added with the vehicle control; dimethyl sulfoxide and the microplates were incubated for 24 or $48 \mathrm{~h}$. Each dosage was repeated in triplicate. MTT $(5 \mathrm{mg} / \mathrm{mL}, 10 \mu \mathrm{L})$ solution was added to every well and incubated for $4 \mathrm{~h}$. After solubilization of the formazan crystals, the colorimetric signal of the plate was measured at $570 \mathrm{~nm}$ (absorbance) and $650 \mathrm{~nm}$ (reference) using a microplate reader. The cell viability was calculated as the percentage change of the absorbance of the treated cells divided by the absorbance of the untreated cells.

\section{Assessment of apoptosis levels via Annexin V/PI staining}

After treatment, the cells were harvested, washed with phosphate-buffered saline (PBS), and resuspended with $1 \mathrm{x}$ binding buffer. Then, the cells were double stained with 
Annexin V/PI for $15 \mathrm{~min}$ at room temperature in the dark. The apoptotic cells were quantitatively counted with a flow cytometer.

\section{Analysis of the mitochondrial membrane potential}

The cell-permeable and mitochondrial-specific fluorescent dye, JC-1, was applied to determine the mitochondrial membrane potential (MMP) of H1975. After treatment, the cells were harvested, washed, and stained with JC-1 for $15 \mathrm{~min}$ in the incubator at $37^{\circ} \mathrm{C}$. Then, the cells were washed again and resuspended with regular medium. The change in the MMP of the cells was measured with a flow cytometer according to the manufacturer's protocol.

\section{Western blot analysis}

Cells were lysed in RIPA lysis buffer with protease and phosphatase inhibitors added to extract the total whole cell protein. The concentration of the total protein extract was determined with a Bio-Rad DCTM Protein Assay Kit. Then, $30 \mu \mathrm{g}$ of total protein lysate was loaded and electrophoresed onto a $10 \%$ sodium dodecyl sulfate-polyacrylamide gel electrophoresis gel; the separated proteins were transferred to a nitrocellulose membrane. Membranes were blocked with 5\% milk without fat in tris-buffered saline and tween 20 (TBST) for $1 \mathrm{~h}$ at room temperature. Primary antibodies (1:500 dilutions; Santa Cruz; 1:1000 dilutions; Invitrogen and Cell Signaling Technology) were incubated overnight at $4^{\circ} \mathrm{C}$. After washing the membrane thrice with TBST ( $5 \mathrm{~min} /$ wash), secondary fluorescent antibody (1:10,000 dilutions) was added to the membrane at room temperature for $1 \mathrm{~h}$. Actin was used as the loading control and for normalization. The signal intensity of the membranes was detected with the LI-COR Odyssey Scanner.

\section{Caspase-3/7 activity assay}

This experiment was guided using the Caspase-GIo 3/7 Assay kit. The assay provides a luminogenic caspase-3/7 substrate, which contains the tetrapeptide sequence DEVD. H1975 cells were seeded on a 96-well plate at a concentration of 5000 cells/well and cultured overnight for cell adhesion. The following day, the cells were treated with a range of concentrations of sanguinarine for $24 \mathrm{~h}$. After treatment, caspase-GIo 3/7 reagent was added to each well of the 96well plate $(100 \mu \mathrm{L} /$ well $)$, and the cells were incubated at room temperature for $1 \mathrm{~h}$; the luminescence signal was measured using a luminometer. The changes of the intensity of luminescence were normalized to the vehicle control.

\section{Reactive oxygen species detection}

The levels of cellular ROS generation were analyzed using fluorescent probe DCFDA staining, which is a specific superoxide tracing dye (39). The cells were pretreated with DCFDA at a working concentration of $20 \mu M$ for $30 \mathrm{~min}$ at $37^{\circ} \mathrm{C}$ before treatment. Then, the cells were incubated with compounds and vehicle control for a specific duration, followed by harvesting and resuspending in PBS. To avoid blocking the pipeline of flow cytometer and assure single cell detection, cell suspension was filtered by Falcon 5-mL disposable sterile round bottom tubes w/Caps. After filtration, the ROS signal was measured with a flow cytometer with excitation and emission settings of 488 and $525 \mathrm{~nm}$, respectively.

\section{Superoxide detection}

The superoxide $\left(\mathrm{O}_{2}^{-}\right)$levels were analyzed using a superoxide detection kit. After drug treatment, the cells were collected and stained with superoxide detection reagent for $30 \mathrm{~min}$ in the dark at $37^{\circ} \mathrm{C}$, followed by two washes with PBS. After filtration, the fluorescence signals of the cells were detected with a flow cytometer.

\section{Clinical sample preparation}

Paired samples of primary NSCLC and normal lung from 60 Chinese patients who underwent surgical resection at the Grantham Hospital, Hong Kong, were prospectively collected and snap-frozen in liquid nitrogen until use. Tumor tissues were examined histologically and microdissected to ensure at least $75 \%$ tumor by area, and normal lung tissues were examined to ensure the absence of tumor.

\section{Kaplan-Meier statistical analysis of clinical results}

Each of the 60 patients was stratified to a high or low NOX2 expression group according to the median value of the tumor/normal relative expression ratio. Statistical analysis was performed using IBM SPSS Statistics, version 20. The correlation with survival data was analyzed using the Kaplan-Meier survival analysis, and a two-sided $p<0.05$ was taken to be the threshold for statistical significance.

\section{Animal xenograft model}

The mixture of $1 \times 10^{6} \mathrm{H} 1975$ cells was resuspended in $100 \mu \mathrm{L}$ of RPMI 1640 medium and $50 \mu \mathrm{L}$ of Matrigel and injected into the armpit of the right forelimb of 6- to 8-weekold nude mice. Five days later, the mice with tumor formation were administered with sanguinarine via i.p. injection and afatinib via intragastric administration 5 days/week 32 for consecutive days. The tumor growth was monitored every 3-4 days using calipers. The tumor volume was calculated using the following equation: volume $=\left(\right.$ width $^{2} \times$ length $) / 2$.

\section{RNA extraction and $c D N A$ synthesis}

RNA was extracted by the RNA extraction kit according to the manufacturer's instructions as previously reported (27). The concentration of RNA was determined using Nano2000, and the quality of RNA was confirmed via electrophoresis. The synthesis of the first strand of cDNA was followed according to the instructions of the cDNA synthesis kit. The final product (cDNA) was stored at $-80^{\circ} \mathrm{C}$ until further use.

\section{PCR and real-time PCR}

PCR products were generated following the instructions of the Taq DNA Polymerase Kit. Primers were designed by Primer 5.0 software according to the sequence of genes from NCBI. Primers used were as follows: NOX1: Forward: TTGTCCGGGGTCAAACAGAG, Reverse: GGGAGTCAC GATCATCCCAC; NOX2: Forward: AAGTGCCCAAAG GTGTCCAA, Reverse: CCCAACGATGCGGATATGGA; NOX3: Forward: AGGGCAGTACATCTTGGTGC, Reverse: CGGATGTGCACGCTGAAAAA; NOX4: Forward: CTACATGCTGCTGACGTTGC, Reverse: CCGGGAGGG TGGGTATCTAA; NOX5: Forward: GCTGTCGAGGAGT GTGACAA, Reverse: CAGAGGCAAAGATCCTGCG; and 
Actin: Forward: AATGAGCGGTTCCGCTGCCC, Reverse: GATGGAGGGGCCGGACTCGT. For clinical samples, the primers of NOX2: Forward: GGTGGCATGGATGATTGCAC, Reverse: CGGGCATTCACACACCATTC, and primers of B2M: Forward: AGGCTATCCAGCGTACTCCA, Reverse: GGCATCTTCAAACCTCCAT-3, were used.

\section{Construct preparation}

The constructs were extracted using a FavorPrep ${ }^{\mathrm{TM}}$ Plasmid DNA Extraction Mini Kit. The sequence of the constructs was confirmed via sequencing, and a large scale of the construct was prepared using a FavorPrep Plasmid DNA Extraction Maxi Kit. The DNA pellet was dissolved in $300 \mu \mathrm{L}$ of $\mathrm{ddH}_{2} \mathrm{O}$.

\section{Transfection}

DNA and siRNA transfections were performed with $\mathrm{Li}$ pofectamine LTX Reagent based on our previous publication (28). Cells were seeded on a six-well plate 1 day before transfection and reached 50\%-80\% confluence at the time of transfection. The DNA or siRNA transfection complexes were prepared as follows: $2 \mu \mathrm{L}$ DNA or $100 \mu M$ siRNA was diluted in $100 \mu \mathrm{L}$ Opti-MEM I Reduced Serum Medium without serum and mixed gently. Lipofectamine LTX Reagent $(4 \mu \mathrm{L})$ was added directly to the diluted DNA. The complexes were incubated for $30 \mathrm{~min}$ at room temperature, and then added to the well. The culture medium and transfection mixture were mixed gently by rocking the plate back and forth. The transgene expression was tested via immunoblotting after incubating the cells at $37^{\circ} \mathrm{C}$ in a $\mathrm{CO}_{2}$ incubator for 24-48 h. The siRNA of NOX3 and MsrA were from Origene, and the Cat. Nos. are TG302912 and SR302974, respectively. They were compared with the nonspecific siRNA control.

\section{The automated LC-MS/MS analysis of the peptides}

After trypsin digestion, EGFR peptide was applied for detection. Ultra-high-performance liquid chromatography was performed using an Agilent 1290 Infinity UHPLC system equipped with a binary solvent delivery system and a standard autosampler. The chromatography was performed on a Waters ACQUITY UPLC ${ }^{\circledR}$ BEH C18 column $(2.1 \times 100 \mathrm{~mm}, 1.7 \mu \mathrm{m})$ (Waters, Milford, MA). The mobile phase consisted of $0.1 \%$ formic acid in Milli-Q water (A) and $0.1 \%$ formic acid in acetonitrile (B). A linear gradient was optimized as follows: $0-20 \mathrm{~min}, 5 \%-80 \% \mathrm{~B} ; 20-23 \mathrm{~min}$, $80 \%-100 \% \mathrm{~B}$; $23-25 \mathrm{~min}, 100 \%-100 \% \mathrm{~B}$; and finally equilibration with $5 \% \mathrm{~B}$ for $3 \mathrm{~min}$ at a flow rate of $0.35 \mathrm{~mL} / \mathrm{min}$. The injection volume was $5 \mu \mathrm{L}$ and the column temperature was maintained at $40^{\circ} \mathrm{C}$. MS was performed on an Agilent 6230 time-of-flight mass spectrometer (TOF/MS). The optimized TOF/MS conditions were as follows: the electrospray ionization (ESI)-MS spectra were acquired in positive modes. Ultrapure nitrogen $\left(\mathrm{N}_{2}\right)$ was used as the nebulizing and sheath gas. Product ion scanning experiments were conducted using ultra-high-purity $\mathrm{N}_{2}$ as collision gas. The ESI parameters were set as follows: the capillary voltage is $4.5 \mathrm{kV}$. The flow rate and temperature of sheath gas were $11 \mathrm{~L} / \mathrm{min}$ and $350^{\circ} \mathrm{C}$, respectively. The flow rate and temperature of drying gas were $11 \mathrm{~L} / \mathrm{min}$ and $300^{\circ} \mathrm{C}$, respec- tively. The pressure of nebulizer gas was $40 \mathrm{psi}$. The fragmentor voltage is $175 \mathrm{~V}$. The mass analyzer was scanned from $\mathrm{m} / \mathrm{z} 100$ to $\mathrm{m} / \mathrm{z} 3200$. The results were analyzed by Agilent Bioconfirm protein deconvolution software.

\section{Molecular docking}

All molecular docking calculations were performed in Schrödinger Suite 2009. The structure of sanguinarine was optimized using the OPLS-2005 force field. The ionized state was assigned using Epik at a target $\mathrm{pH}$ value of $7.0 \pm 2.0$. The crystal structures of WT and double-mutant EGFR were retrieved from the Protein Data Bank (PDB ID: 3W2S, 3W2R) $(35,59)$. Protein Preparation Wizard was used to remove crystallographic water molecules, add hydrogen atoms, assign partial charges, and protonate states using the OPLS2005 force field. Sanguinarine was docked into the binding site of the EGFR using the Glide program with the extra precision scoring mode. In molecular docking, 5000 poses were generated during the initial phase of the docking calculation, of which the best 1000 poses were chosen for energy minimization via 1000 steps of conjugate gradient minimizations.

\section{Immunofluorescence}

A sterile cover slide was placed in a six-well plate. Cells were seeded into the plate and cultured overnight for cell adhesion. After treatment, the cells were fixed with $1 \mathrm{~mL}$ of 4\% PFA for $15 \mathrm{~min}$, and then washed with PBS thrice. Triton $\mathrm{X}-100(1 \mathrm{~mL}$ of $0.1 \%)$ was added to the cells and incubated for 5 min to penetrate the cell membrane; the cells were washed thrice with PBS. After $1 \mathrm{~h}$ of blocking in normal serum from the same species as the secondary antibody, the cells were incubated with primary antibody in blocking solution (1:500 dilution) at $4^{\circ} \mathrm{C}$ overnight and washed thrice in PBS. Then, the cells were incubated in fluorochromeconjugated secondary antibody that was diluted in blocking solution (1:500) for $1 \mathrm{~h}$ at room temperature in the dark. Finally, cover slides were fixed with Prolong Gold Antifade Reagent with DAPI. The immunofluorescence images were captured with the DeltaVision Live Cell Imaging System.

\section{NADP/NADPH-Glo assay}

Cells were seeded in a 96-well plate ( 5000 cells/well) 1 day before treatment. The next day, the cells were treated with a series of sanguinarine concentrations for $1 \mathrm{~h}$; the medium was then replaced with $50 \mu \mathrm{L}$ of $\mathrm{PBS} /$ well. The plates were equilibrated at room temperature for $5 \mathrm{~min}$. NADP/NADPHGIo detection reagent $(50 \mu \mathrm{L})$ was added to each well and incubated for 30-60 min at room temperature. Finally, luminescence was detected with a luminometer.

\section{Statistical analysis}

All data are expressed as the mean \pm SEM of three independent experiments. Differences between groups were determined using one-way analysis of variance using GraphPad Prism 5, which was followed by Bonferroni's test to compare all pairs of columns. Student's $t$-test was used for comparing two groups. The level of significance was set at $p<0.05$ for all tests. 


\section{Acknowledgments}

This work was supported by FDCT grants from the Science and Technology Development Fund of Macao (Project code: 074/2011/A3 021/2013/A1 and 005/2014/AMJ) to E.L.L. and a grant from the Key International Joint Research Project of the National Natural Science Foundation of China (No. $81120108025)$ to Z.Q.L.

\section{Author Contributions}

L.L. and E.L.H.L. conceived the study, designed the experiments, supervised all research, and revised the manuscript. E.L.H.L., X.X.F., and Y.L.Z. carried out the experiments and analyzed the data. E.L.H.L. and X.X.F. prepared the draft of the manuscript. Z.H.J. designed and L.F.Y. performed the mass spectrometry experiments. X.J.Y. conducted the computational docking. V.P.C.T. performed realtime PCR of clinical samples, and M.P.W. collected clinical samples as well as performed the pathology analysis. L.L.L., Y.L.Z., and Z.Q.L. carried out the animal studies.

\section{Author Disclosure Statement}

No competing financial interests exist.

\section{References}

1. Alpha-Tocopherol, Beta Carotene Cancer Prevention Study Group. The effect of vitamin $\mathrm{E}$ and beta carotene on the incidence of lung cancer and other cancers in male smokers. N Engl J Med 330: 1029-1035, 1994.

2. Bean J, Brennan C, Shih JY, Riely G, Viale A, Wang L, Chitale D, Motoi N, Szoke J, Broderick S, Balak M, Chang WC, Yu CJ, Gazdar A, Pass H, Rusch V, Gerald W, Huang SF, Yang PC, Miller V, Ladanyi M, Yang CH, and Pao W. MET amplification occurs with or without T790M mutations in EGFR mutant lung tumors with acquired resistance to gefitinib or erlotinib. Proc Natl Acad Sci U S A 104: 20932-20937, 2007.

3. Bell DW, Gore I, Okimoto R, Godin-Heymann N, Sordella R, Mulloy R, Sharma SV, Brannigan BW, Mohapatra G, Settleman J, and Haber DA. Inherited susceptibility to lung cancer may be associated with the T790M drug resistance mutation in EGFR. Nat Genet 37: 1315-1316, 2005.

4. Breusing $\mathrm{N}$ and Grune $\mathrm{T}$. Regulation of proteasomemediated protein degradation during oxidative stress and aging. Biol Chem 389: 203-209, 2008.

5. Brown DI and Griendling KK. Nox proteins in signal transduction. Free Radic Biol Med 47: 1239-1253, 2009.

6. Cairns RA, Harris IS, and Mak TW. Regulation of cancer cell metabolism. Nat Rev Cancer 11: 85-95, 2011.

7. Chondrogianni N, Petropoulos I, Grimm S, Georgila K, Catalgol B, Friguet B, Grune T, and Gonos ES. Protein damage, repair and proteolysis. Mol Aspects Med 35: 1-71, 2014.

8. Chong CR and Janne PA. The quest to overcome resistance to EGFR-targeted therapies in cancer. Nat Med 19: 13891400, 2013.

9. Cross DA, Ashton SE, Ghiorghiu S, Eberlein C, Nebhan CA, Spitzler PJ, Orme JP, Finlay MR, Ward RA, Mellor MJ, Hughes G, Rahi A, Jacobs VN, Red Brewer M, Ichihara E, Sun J, Jin H, Ballard P, Al-Kadhimi K, Rowlinson R, Klinowska T, Richmond GH, Cantarini M, Kim DW, Ranson MR, and Pao W. AZD9291, an irreversible EGFR
TKI, overcomes T790M-mediated resistance to EGFR inhibitors in lung cancer. Cancer Discov 4: 1046-1061, 2014.

10. Debiton E, Madelmont JC, Legault J, and Barthomeuf C. Sanguinarine-induced apoptosis is associated with an early and severe cellular glutathione depletion. Cancer Chemother Pharmacol 51: 474-482, 2003.

11. Diet A, Abbas K, Bouton C, Guillon B, Tomasello F, Fourquet S, Toledano MB, and Drapier JC. Regulation of peroxiredoxins by nitric oxide in immunostimulated macrophages. J Biol Chem 282: 36199-36205, 2007.

12. Dong XZ, Zhang M, Wang K, Liu P, Guo DH, Zheng XL, and Ge XY. Sanguinarine inhibits vascular endothelial growth factor release by generation of reactive oxygen species in MCF-7 human mammary adenocarcinoma cells. Biomed Res Int 2013: 517698, 2013.

13. Dorrestein PC and Carroll KS. 'Omics' of natural products and redox biology. Curr Opin Chem Biol 15: 3-4, 2011.

14. Eskens FA, Mom CH, Planting AS, Gietema JA, Amelsberg A, Huisman H, van Doorn L, Burger H, Stopfer P, Verweij J, and de Vries EG. A phase I dose escalation study of BIBW 2992, an irreversible dual inhibitor of epidermal growth factor receptor 1 (EGFR) and 2 (HER2) tyrosine kinase in a 2-week on, 2-week off schedule in patients with advanced solid tumours. Br J Cancer 98: 80-85, 2008.

15. Glasauer A, Sena LA, Diebold LP, Mazar AP, and Chandel NS. Targeting SOD1 reduces experimental non-small-cell lung cancer. J Clin Invest 124: 117-128, 2014.

16. Goodson WH 3rd, Lowe L, Carpenter DO, Gilbertson M, Manaf Ali A, Lopez de Cerain Salsamendi A, Lasfar A, Carnero A, Azqueta A, Amedei A, Charles AK, Collins AR, Ward A, Salzberg AC, Colacci A, Olsen AK, Berg A, Barclay BJ, Zhou BP, Blanco-Aparicio C, Baglole CJ, Dong C, Mondello C, Hsu CW, Naus CC, Yedjou C, Curran CS, Laird DW, Koch DC, Carlin DJ, Felsher DW, Roy D, Brown DG, Ratovitski E, Ryan EP, Corsini E, Rojas E, Moon EY, Laconi E, Marongiu F, Al-Mulla F, Chiaradonna F, Darroudi F, Martin FL, Van Schooten FJ, Goldberg GS, Wagemaker G, Nangami G, Calaf GM, Williams G, Wolf GT, Koppen G, Brunborg G, Kim Lyerly H, Krishnan H, Ab Hamid H, Yasaei H, Sone H, Kondoh H, Salem HK, Hsu HY, Park HH, Koturbash I, Miousse IR, Scovassi AI, Klaunig JE, Vondracek J, Raju J, Roman J, Wise JP, Sr., Whitfield JR, Woodrick J, Christopher JA, Ochieng J, Martinez-Leal JF, Weisz J, Kravchenko J, Sun J, Prudhomme KR, Narayanan KB, Cohen-Solal KA, Moorwood K, Gonzalez L, Soucek L, Jian L, D'Abronzo LS, Lin LT, Li L, Gulliver L, McCawley LJ, Memeo L, Vermeulen L, Leyns L, Zhang L, Valverde M, Khatami M, Romano MF, Chapellier M, Williams MA, Wade M, Manjili MH, Lleonart M, Xia M, Gonzalez MJ, Karamouzis MV, Kirsch-Volders M, Vaccari M, Kuemmerle NB, Singh N, Cruickshanks N, Kleinstreuer N, van Larebeke N, Ahmed N, Ogunkua O, Krishnakumar PK, Vadgama P, Marignani PA, Ghosh PM, Ostrosky-Wegman P, Thompson P, Dent P, Heneberg P, Darbre P, Sing Leung P, Nangia-Makker P, Cheng QS, Robey RB, Al-Temaimi R, Roy R, AndradeVieira R, Sinha RK, Mehta R, Vento R, Di Fiore R, PonceCusi R, Dornetshuber-Fleiss R, Nahta R, Castellino RC, Palorini R, Abd Hamid R, Langie SA, Eltom S, Brooks SA, Ryeom S, Wise SS, Bay SN, Harris SA, Papagerakis S, Romano S, Pavanello S, Eriksson S, Forte S, Casey SC, Luanpitpong S, Lee TJ, Otsuki T, Chen T, Massfelder T, Sanderson T, Guarnieri T, Hultman T, Dormoy V, OderoMarah V, Sabbisetti V, Maguer-Satta V, Rathmell WK, 
Engstrom W, Decker WK, Bisson WH, Rojanasakul Y, Luqmani Y, Chen Z, and $\mathrm{Hu} \mathrm{Z}$. Assessing the carcinogenic potential of low-dose exposures to chemical mixtures in the environment: the challenge ahead. Carcinogenesis $36 \mathrm{Suppl}$ 1: S254-S296, 2015.

17. Gorrini C, Harris IS, and Mak TW. Modulation of oxidative stress as an anticancer strategy. Nat Rev Drug Discov 12: 931-947, 2013.

18. Hamanaka RB and Chandel NS. Mitochondrial reactive oxygen species regulate hypoxic signaling. Curr Opin Cell Biol 21: 894-899, 2009.

19. Hamanaka RB and Chandel NS. Cell biology. Warburg effect and redox balance. Science 334: 1219-1220, 2011.

20. Hoshi $\mathrm{T}$ and Heinemann S. Regulation of cell function by methionine oxidation and reduction. J Physiol 531: 1-11, 2001.

21. Hur W and Gray NS. Small molecule modulators of antioxidant response pathway. Curr Opin Chem Biol 15: 162 173, 2011.

22. Jang BC, Park JG, Song DK, Baek WK, Yoo SK, Jung KH, Park GY, Lee TY, and Suh SI. Sanguinarine induces apoptosis in A549 human lung cancer cells primarily via cellular glutathione depletion. Toxicol In Vitro 23: 281-287, 2009.

23. Kan J, Guo W, Huang C, Bao G, Zhu Y, and Zhu YZ. Spropargyl-cysteine, a novel water-soluble modulator of endogenous hydrogen sulfide, promotes angiogenesis through activation of signal transducer and activator of transcription 3. Antioxid Redox Signal 20: 2303-2316, 2014.

24. Kim HP, Han SW, Kim SH, Im SA, Oh DY, Bang YJ, and Kim TY. Combined lapatinib and cetuximab enhance cytotoxicity against gefitinib-resistant lung cancer cells. Mol Cancer Ther 7: 607-615, 2008.

25. Kim Y, Ko J, Cui Z, Abolhoda A, Ahn JS, Ou SH, Ahn MJ, and Park K. The EGFR T790M mutation in acquired resistance to an irreversible second-generation EGFR inhibitor. Mol Cancer Ther 11: 784-791, 2012.

26. Lee HJ, Schaefer G, Heffron TP, Shao L, Ye X, Sideris S, Malek S, Chan E, Merchant M, La H, Ubhayakar S, Yauch RL, Pirazzoli V, Politi K, and Settleman J. Noncovalent wild-type-sparing inhibitors of EGFR T790M. Cancer Discov 3: 168-181, 2013.

27. Leung EL, Fiscus RR, Tung JW, Tin VP, Cheng LC, Sihoe AD, Fink LM, Ma Y, and Wong MP. Non-small cell lung cancer cells expressing CD44 are enriched for stem celllike properties. PloS One 5: e14062, 2010.

28. Leung EL, Tam IY, Tin VP, Chua DT, Sihoe AD, Cheng LC, Ho JC, Chung LP, and Wong MP. SRC promotes survival and invasion of lung cancers with epidermal growth factor receptor abnormalities and is a potential candidate for molecular-targeted therapy. Mol Cancer Res 7: 923-932, 2009.

29. Liu L, Leung EL, and Tian X. Perspective: the clinical trial barriers. Nature 480: S100, 2011.

30. Lynch TJ, Bell DW, Sordella R, Gurubhagavatula S, Okimoto RA, Brannigan BW, Harris PL, Haserlat SM, Supko JG, Haluska FG, Louis DN, Christiani DC, Settleman J, and Haber DA. Activating mutations in the epidermal growth factor receptor underlying responsiveness of non-small-cell lung cancer to gefitinib. NEngl J Med 350: 2129-2139, 2004.

31. Matkar SS, Wrischnik LA, and Hellmann-Blumberg U. Production of hydrogen peroxide and redox cycling can explain how sanguinarine and chelerythrine induce rapid apoptosis. Arch Biochem Biophys 477: 43-52, 2008.

32. Molenaar RJ and van Noorden CJ. Type 2 diabetes and cancer as redox diseases? Lancet 384: 853, 2014.
33. Murphy MP, Holmgren A, Larsson NG, Halliwell B, Chang CJ, Kalyanaraman B, Rhee SG, Thornalley PJ, Partridge L, Gems D, Nystrom T, Belousov V, Schumacker PT, and Winterbourn CC. Unraveling the biological roles of reactive oxygen species. Cell Metab 13: 361-366, 2011.

34. Nakano Y, Banfi B, Jesaitis AJ, Dinauer MC, Allen LA, and Nauseef WM. Critical roles for p22phox in the structural maturation and subcellular targeting of Nox3. Biochem J 403: 97-108, 2007.

35. Pan D, Xue W, Wang X, Guo J, Liu H, and Yao X. Molecular mechanism of the enhanced virulence of 2009 pandemic influenza A (H1N1) virus from D222G mutation in the hemagglutinin: a molecular modeling study. $\mathrm{J} \mathrm{Mol}$ Model 18: 4355-4366, 2012.

36. Pao W, Miller VA, Politi KA, Riely GJ, Somwar R, Zakowski MF, Kris MG, and Varmus H. Acquired resistance of lung adenocarcinomas to gefitinib or erlotinib is associated with a second mutation in the EGFR kinase domain. PLoS Med 2: e73, 2005.

37. Paulsen CE, Truong TH, Garcia FJ, Homann A, Gupta V, Leonard SE, and Carroll KS. Peroxide-dependent sulfenylation of the EGFR catalytic site enhances kinase activity. Nat Chem Biol 8: 57-64, 2012.

38. Prabhakar NR, Kumar GK, Nanduri J, and Semenza GL. ROS signaling in systemic and cellular responses to chronic intermittent hypoxia. Antioxid Redox Signal 9: 1397-1403, 2007.

39. Raj L, Ide T, Gurkar AU, Foley M, Schenone M, Li X, Tolliday NJ, Golub TR, Carr SA, Shamji AF, Stern AM, Mandinova A, Schreiber SL, and Lee SW. Selective killing of cancer cells by a small molecule targeting the stress response to ROS. Nature 475: 231-234, 2011.

40. Regales L, Gong Y, Shen R, de Stanchina E, Vivanco I, Goel A, Koutcher JA, Spassova M, Ouerfelli O, Mellinghoff IK, Zakowski MF, Politi KA, and Pao W. Dual targeting of EGFR can overcome a major drug resistance mutation in mouse models of EGFR mutant lung cancer. $J$ Clin Invest 119: 3000-3010, 2009.

41. Rosell R, Bivona TG, and Karachaliou N. Genetics and biomarkers in personalisation of lung cancer treatment. Lancet 382: 720-731, 2013.

42. Rosell R and Karachaliou N. Lung cancer: maintenance therapy and precision medicine in NSCLC. Nat Rev Clin Oncol 10: 549-550, 2013.

43. Sauer H, Wartenberg M, and Hescheler J. Reactive oxygen species as intracellular messengers during cell growth and differentiation. Cell Physiol Biochem 11: 173-186, 2001.

44. Sayin VI, Ibrahim MX, Larsson E, Nilsson JA, Lindahl P, and Bergo MO. Antioxidants accelerate lung cancer progression in mice. Sci Transl Med 6: 221ra15, 2014.

45. Sebastian S, Settleman J, Reshkin SJ, Azzariti A, Bellizzi A, and Paradiso A. The complexity of targeting EGFR signalling in cancer: from expression to turnover. Biochim Biophys Acta 1766: 120-139, 2006.

46. Sequist LV, Waltman BA, Dias-Santagata D, Digumarthy S, Turke AB, Fidias P, Bergethon K, Shaw AT, Gettinger S, Cosper AK, Akhavanfard S, Heist RS, Temel J, Christensen JG, Wain JC, Lynch TJ, Vernovsky K, Mark EJ, Lanuti M, Iafrate AJ, Mino-Kenudson M, and Engelman JA. Genotypic and histological evolution of lung cancers acquiring resistance to EGFR inhibitors. Sci Transl Med 3: 75ra26, 2011.

47. Sharma SV, Bell DW, Settleman J, and Haber DA. Epidermal growth factor receptor mutations in lung cancer. Nat Rev Cancer 7: 169-181, 2007. 
48. Shtiegman K, Kochupurakkal BS, Zwang Y, Pines G, Starr A, Vexler A, Citri A, Katz M, Lavi S, Ben-Basat Y, Benjamin S, Corso S, Gan J, Yosef RB, Giordano S, and Yarden Y. Defective ubiquitinylation of EGFR mutants of lung cancer confers prolonged signaling. Oncogene 26: 6968-6978, 2007.

49. Somwar R, Erdjument-Bromage H, Larsson E, Shum D, Lockwood WW, Yang G, Sander C, Ouerfelli O, Tempst PJ, Djaballah H, and Varmus HE. Superoxide dismutase 1 (SOD1) is a target for a small molecule identified in a screen for inhibitors of the growth of lung adenocarcinoma cell lines. Proc Natl Acad Sci U S A 108: 16375-16380, 2011.

50. Sordella R, Bell DW, Haber DA, and Settleman J. Gefitinibsensitizing EGFR mutations in lung cancer activate antiapoptotic pathways. Science 305: 1163-1167, 2004.

51. Stone JR and Yang S. Hydrogen peroxide: a signaling messenger. Antioxid Redox Signal 8: 243-270, 2006.

52. Sugden PH and Clerk A. Oxidative stress and growthregulating intracellular signaling pathways in cardiac myocytes. Antioxid Redox Signal 8: 2111-2124, 2006.

53. Tam IY, Leung EL, Tin VP, Chua DT, Sihoe AD, Cheng LC, Chung LP, and Wong MP. Double EGFR mutants containing rare EGFR mutant types show reduced in vitro response to gefitinib compared with common activating missense mutations. Mol Cancer Ther 8: 2142-2151, 2009.

54. Tarrago L, Kaya A, Weerapana E, Marino SM, and Gladyshev VN. Methionine sulfoxide reductases preferentially reduce unfolded oxidized proteins and protect cells from oxidative protein unfolding. J Biol Chem 287: 2444824459, 2012.

55. Trachootham D, Alexandre J, and Huang P. Targeting cancer cells by ROS-mediated mechanisms: a radical therapeutic approach? Nat Rev Drug Discov 8: 579-591, 2009.

56. Truong TH and Carroll KS. Redox regulation of epidermal growth factor receptor signaling through cysteine oxidation. Biochemistry 51: 9954-9965, 2012.

57. Watson JD. Type 2 diabetes as a redox disease. Lancet 383 : 841-843, 2014.

58. Xu JY, Meng QH, Chong Y, Jiao Y, Zhao L, Rosen EM, and Fan S. Sanguinarine is a novel VEGF inhibitor involved in the suppression of angiogenesis and cell migration. Mol Clin Oncol 1: 331-336, 2013.

59. Xue W, Qi J, Yang Y, Jin X, Liu H, and Yao X. Understanding the effect of drug-resistant mutations of HIV-1 intasome on raltegravir action through molecular modeling study. Mol Biosyst 8: 2135-2144, 2012.

60. Yu HA and Pao W. Targeted therapies: afatinib-new therapy option for EGFR-mutant lung cancer. Nat Rev Clin Oncol 10: 551-552, 2013.
Address correspondence to:

Prof. Liang Liu

State Key Laboratory of Quality Research

in Chinese Medicine

Macau Institute for Applied Research

in Medicine and Health

Macau University of Science and Technology

Avenida Wai Long

Taipa, Macau

China

E-mail: 1liu@must.edu.mo

Date of first submission to ARS Central, June 16, 2015; date of final revised submission, October 16, 2015; date of acceptance, October 28, 2015.

\begin{tabular}{|c|}
\hline Abbreviations Used \\
\hline Cys $^{797}=$ cysteine at position 797 \\
\hline DCFDA $=$ dichlorofluorescein diacetate \\
\hline DPI = diphenyleneiodonium \\
\hline $\mathrm{EGFR}=$ epidermal growth factor receptor \\
\hline $\mathrm{H}_{2} \mathrm{O}_{2}=$ hydrogen peroxide \\
\hline i.p. $=$ intraperitoneal \\
\hline M790 = methionine 790 \\
\hline Met $=$ methionine \\
\hline $\mathrm{MMP}=$ mitochondrial membrane potential \\
\hline $\mathrm{MS}=$ mass spectrometry \\
\hline $\mathrm{Msr} \mathrm{A}=$ methionine reductase $\mathrm{A}$ \\
\hline $\begin{array}{c}\text { MTT }=3 \text {-(4,5-dimethylthiazol-2-yl)-2,5- } \\
\text { diphenyltetrazolium bromide }\end{array}$ \\
\hline $\mathrm{N}_{2}=$ nitrogen \\
\hline $\mathrm{NAC}=\mathrm{N}$-acetyl-1-cysteine \\
\hline $\mathrm{NOX}=\mathrm{NADPH}$ oxidase \\
\hline NSCLC $=$ non-small cell lung cancer cell \\
\hline $\mathrm{O}_{2}^{-}=$superoxide \\
\hline $\mathrm{PBS}=$ phosphate-buffered saline \\
\hline $\begin{array}{c}\mathrm{Q}-\mathrm{PCR}=\text { quantitative real-time polymerase chain } \\
\text { reaction }\end{array}$ \\
\hline $\mathrm{RIPA}=$ radioimmunoprecipitation assay \\
\hline ROS $=$ reactive oxygen species \\
\hline siRNA $=$ small interfering RNA \\
\hline SOD1 $=$ superoxide dismutase 1 \\
\hline $\begin{array}{r}\mathrm{T} 790 \mathrm{M}=\mathrm{a} \text { substitution mutation of threonine with } \\
\text { methionine at position } 790 \text { of EGFR }\end{array}$ \\
\hline TKIs $=$ tyrosine kinase inhibitors \\
\hline $\mathrm{TOF} / \mathrm{MS}=$ time-of-flight mass spectrometer \\
\hline $\mathrm{WT}=$ wild-type \\
\hline
\end{tabular}

